\title{
PROMETHEE-SAPEVO-M1 a Hybrid Approach Based on Ordinal and Cardinal Inputs: Multi-Criteria Evaluation of Helicopters to Support Brazilian Navy Operations
}

\author{
Miguel Ângelo Lellis Moreira 1,2,3,*(D), Igor Pinheiro de Araújo Costa 2 (D), Maria Teresa Pereira 4,5, \\ Marcos dos Santos 1,3 ${ }^{1}$, Carlos Francisco Simões Gomes ${ }^{2}(\mathbb{D})$ and Fernando Martins Muradas ${ }^{3}$ \\ 1 Systems and Computing Department, Military Institute of Engineering (IME), Urca 22290-270, Brazil; \\ marcosdossantos@ime.eb.br \\ 2 Production Department, Fluminense Federal University (UFF), Niterói 24210-346, Brazil; \\ igorpin89@gmail.com (I.P.d.A.C.); cfsg1@bol.com.br (C.F.S.G.) \\ 3 Operational Research Department, Naval Systems Analysis Center (CASNAV), \\ Rio de Janeiro 20091-000, Brazil; fernando.muradas@marinha.mil.br \\ 4 Centre for Research \& Development in Mechanical Engineering (CIDEM), School of Engineering of \\ Porto (ISEP), Polytechnic of Porto, 4200-072 Porto, Portugal; mtp@isep.ipp.pt \\ 5 INEGI-Instituto de Ciência e Inovação em Engenharia Mecânica e Engenharia Industrial, \\ Rua Dr. Roberto Frias, 400, 4200-465 Porto, Portugal \\ * Correspondence: miguellellis@ime.eb.br
}

Citation: Moreira, M.Â.L.; de Araújo Costa, I.P.; Pereira, M.T.; dos Santos, M.; Gomes, C.F.S.; Muradas, F.M PROMETHEE-SAPEVO-M1 a Hybrid Approach Based on Ordinal and Cardinal Inputs: Multi-Criteria Evaluation of Helicopters to Support Brazilian Navy Operations. Algorithms 2021, 14, 140. https:// doi.org/10.3390/a14050140

Academic Editors: Francisco Javier Santos-Arteaga and Debora Di Caprio

Received: 22 March 2021

Accepted: 19 April 2021

Published: 27 April 2021

Publisher's Note: MDPI stays neutral with regard to jurisdictional claims in published maps and institutional affiliations.

Copyright: (c) 2021 by the authors Licensee MDPI, Basel, Switzerland. This article is an open access article distributed under the terms and conditions of the Creative Commons Attribution (CC BY) license (https:// creativecommons.org/licenses/by/ $4.0 /)$.
Abstract: This paper presents a new approach based on Multi-Criteria Decision Analysis (MCDA), named PROMETHEE-SAPEVO-M1, through its implementation and feasibility related to the decisionmaking process regarding the evaluation of helicopters of attack of the Brazilian Navy. The proposed methodology aims to present an integration of ordinal evaluation into the cardinal procedure from the PROMETHEE method, enabling to perform qualitative and quantitative data and generate the criteria weights by pairwise evaluation, transparently. The modeling provides three models of preference analysis, as partial, complete, and outranking by intervals, along with an intra-criterion analysis by veto threshold, enabling the analysis of the performance of an alternative in a specific criterion. As a demonstration of the application, is carried out a case study by the PROMETHEESAPEVO-M1 web platform, addressing a strategic analysis of attack helicopters to be acquired by the Brazilian Navy, from the need to be evaluating multiple specifications with different levels of importance within the context problem. The modeling implementation in the case study is made in detail, first performing the alternatives in each criterion and then presenting the results by three different models of preference analysis, along with the intra-criterion analysis and a rank reversal procedure. Moreover, is realized a comparison analysis to the PROMETHEE method, exploring the main features of the PROMETHEE-SAPEVO-M1. Moreover, a section of discussion is presented, exposing some features and main points of the proposal. Therefore, this paper provides a valuable contribution to academia and society since it represents the application of an MCDA method in the state of the art, contributing to the decision-making resolution of the most diverse real problems.

Keywords: multi-criteria decision analysis; decision support systems; PROMETHEE method; military aircraft

\section{Introduction}

Based on the Brazilian Federal Constitution [1], the Brazilian Navy (BN) aims to prepare and employ naval power contributing to the defense of the country, guaranteeing constitutional powers and ensuring law and order, fulfilling the duties provided by the law, with emphasis on those related to the Maritime Authority, aiming to contribute to safeguarding national interests [2]. 
Even in a time of peace, it is essential that the BN has modern equipment to guarantee its sovereignty and strategic interests that support Brazil foreign policy and positions in international forums [3]. In 2019, a document entitled Naval Policy (NP) was promulgated by the BN. The NP guides, following the National Defense Strategy (NDS), the BN strategic planning, whose compliance imposes the availability of marine forces able to act in line with the political-strategic and economic magnitude of Brazil in the international scenario [4].

According to the objectives and guidelines established in the National Defense Policy (NDP) and NDS, high-level documents that condition the preparation and use of the Armed Forces, $\mathrm{BN}$ is responsible for the use of the Naval Power, providing sufficient capacity and credibility to deter any adverse forces from conducting hostile actions in Brazilian Jurisdictional Waters (BJW) [4].

The presence of marine units in the South Atlantic, where the "Blue Amazon" is included, and in the rivers of the Amazon and Paraguay-Paraná basins will be an essential factor for strengthening this dissuasion. Thus, the Force must be prepared both to act in an interstate crisis and to monitor and suppress the actions of adverse groups practicing illegal activities in BJW [5]. Highlighting that the addressed problem provides influence in local and external perspectives presented in the context [6].

Since the first version of the NDS set the mission to raise the level of the Brazilian Armed Forces, each Force has presented its conception of military change, the Brazilian Navy prioritized modernization [7]. The Naval Power comprises the ability to use the sea and inland waters, at the disposal of a force with expeditionary property, in a permanent condition of prompt employment, ensuring the projection of power over the land. This force is composed of an amphibian conjugate: Naval Force, an Operative Group of Marines, and the Air Force, in a position to fulfill missions related to the basic tasks of the Naval Power [8].

In this context, among the military aircrafts necessary for carrying out aero-naval missions, we highlight the use of attack helicopters, suitable for reconnaissance and air fire support activities, due to their large number of armaments and ability to engage air and ground targets. This function is currently performed by helicopters of smaller size and with low firepower, although, could be replaced by more modern means specific for this purpose, thus, ensuring better performance in the execution of such activities [9].

Thus, it would be of great value to the Marine Corps that the BN acquires new helicopters with the capabilities to provide the necessary fire support to Amphibious Operations, capable of carrying out advanced aerial reconnaissance and offensive air support, mainly in the fight against armored vehicles and enemy troops on the ground. The NDS provides, under the leadership of the Ministry of Defense, the acquisition of transport helicopters, reconnaissance, and attack, acquired with commercial, industrial, and technological compensation [10].

Considering this need, due to the quantity, diversity, and complexity of existing models today, the task of selecting a helicopter that is more appropriate to BN's needs, aiming to provide support to the operations performed by the CFN, is not a simple task. The models of helicopters currently used in the main Armed Forces of the world can be analyzed in the light of various criteria, whether qualitative or quantitative, such as speed, armaments, autonomy, load capacity, and some more complex, such as maneuverability, systems, and aggregate technologies [11].

In this context, of several alternatives, criteria, and complex scenarios, the MultiCriteria Decision Analysis (MCDA) can be favorable to support the decision-making process, presenting techniques that allow the decision-maker to structure and evaluate complex problems transparently, introducing quantitative and qualitative criteria [12-14], defining the importance of variables in an interactive process with other technical-political actors [15]. Contemplating the context of multi-criteria analysis regarding the evaluation of actions in defense scenarios, some previous studies are presented in [16-20].

In a real decision-making problem, uncertainty is intrinsic. As suggested by Malloy et al. [21], MCDA methods should enable an integrated algorithm, providing to perform 
qualitative and quantitative data, in other words, enabling to evaluate variables based on subjective information, along with data in a quantitative format. In the decision analysis, the presence of uncertainty and subjectivity information is natural [22], considering that obtained information can present a lack of complete data or certainty [23]. In this context, aspects of subjectivity in the MCDA methods play an important role [24], transcribing the preferences of the decision-maker by the modeling, being clear concerning the manipulations and attributions regarding the problem in evaluation [25].

This paper aims to present a case study based on the MCDA methodology through a proposal of a new variant of the family of methods PROMETHEE (Preference Ranking Organization Method for Enrichment Evaluations) [26]. The hybrid modeling, named PROMETHEE-SAPEVO-M1, represents the integration of two methodological concepts, one intended on cardinal evaluation and the other relative to ordinal evaluation. The algorithm enables the analysis of a set of alternatives considering both quantitative and qualitative criteria, structuring the weights of criteria by ordinal inputs, and exploring the results by three different models of preference analysis along with an intra-criterion analysis by veto threshold. Considering a hypothetical situation of new aircraft acquisitions, the study aims to provide a fundamental procedure to decision-making, to the $\mathrm{BN}$, in search to obtain a ranking of the helicopters and identify the most favorable between them.

The article is structured into six sections. After the introduction, Section 2 explores the theoretical foundation related to the concepts of MCDA, the base methods related to the proposal, and introduces the new purpose; Section 3 presents the axiomatic structuring of the PROMETHEE-SAPEVO-M1 followed by the numerical implementation related to the case study in Section 4; Section 5 presents a discussion, exploring the main points related to the new proposal and its correlation to the case study, and in Section 6 the research findings are concluded.

\section{Multi-Criteria Decision Analysis}

Decision-making, as old as civilization, is integrated into human activity, being characterized as the analysis process of a set of actions in search of obtaining a favorable solution for a problem [27]. As observed by Maghrabie et al. [28], with the involvement of multiple circumstances and scenarios, the complexity of the analysis is increased, from the moment that there are different points of view and perspectives related to the importance or preference of a variable, being necessary to consider for a substantial analysis and assertive decision-making [29].

The MCDA is the Operational Research field that allows the structuring and understanding of a problem in complex environments, considering risk and uncertainty, transparently [30,31], assisting in obtaining answers to problems of a varied nature [32]. The MCDA methods establish the preferences between the alternatives under criteria, which are usually conflicting $[33,34]$. Commonly four types of approaches are used as the format of solution recommendation [35,36]: choice problems identifying the most favorable alternative in a global context; ranking problems identifying the alternatives from the most favorable to the least favorable; sorting problems allocating the alternatives into clusters of dominance; and portfolio problems choosing a subset of the alternatives set regarding the objectives and constraints in the analysis.

As presented in [37], a great tendency present in research related to AMD methods is a combination of two or more methods; it cures the application of one method to compensate for the absence or deficiency of some technique present to the other, defeated in the construction of a new model of decision analysis.

One of the main integration models concerns the joining of a method to evaluate the criteria and obtain their respective weights, providing the values of importance and another method that is responsible for the aggregation of preference relations and, finally, representation of global solutions, as presented in [38-41]. 


\subsection{PROMETHEE Method}

The PROMETHEE method, proposed by Brans, Vincke, and Mareschal in 1984 [42], is a non-compensatory method handling ranking problems, evaluating a set of alternatives under multi-criteria, which are often conflicting [43]. The modeling establishes a preference structure between the alternatives, considering a preference function, defined by the decision-maker, for each criterion, obtaining a partial and complete ranking of the alternatives [42].

As exposed in [44], one of the main characteristics of the PROMETHEE method is simplicity, clarity, and stability, where is used the notion of a generalized criterion to construct outranking. The methodology is presented as a family of methods, by the moment that researchers proposed new variants in the last years and, according to Behzadian et al. [45], the number of applications working with the PROMETHEE method is increasing year by year, being present in many and varied areas and studies, such as Environment, Logistic and Transportation, Business, Manufacturing, Chemistry, Energy Management, Social, Medicine, Education, Sports, etc.

The PROMETHEE procedure has as basis the pairwise comparison evaluation between the alternatives belonging to set $A$, being necessary for the decision-maker to indicate some attributes, as preference functions, thresholds, and criteria weights [46]. The process starts with the definition of the performance of alternatives in each criterion, as maximization function $d\left(a_{1}, a_{2}\right)=f\left(a_{1}\right)-\left(a_{2}\right)$ or minimization function $d\left(a_{1}, a_{2}\right)=f\left(a_{2}\right)-\left(a_{1}\right)$.

The value $d\left(a_{1}, a_{2}\right)$ represents the difference between $a_{1}$ and $a_{2}$, and it is necessary to define a preference function enabling to stablish a preference degree $[0,1]$, indicating the preference relation $P\left(a_{1}, a_{2}\right)$ in each criterion. As presented in [47], it is possible to use six types of generalized functions, where according to each function, may be requested a preference or indifference threshold.

To obtain the preference relations degree between alternatives, it is necessary to indicate the criteria weights, representing the relative importance of each criterion. Then a Preference Global Index is obtained, indicating the global preference between a pair of alternatives, enabling generating the outranking flows, representing the performance of each alternative regarding the other in the problem context.

\section{Variants of the PROMETHEE Method}

In the last years, new models were developed based on the PROMETHEE method, bringing approaches presented by the integration of methods, fuzzy applications, models for group decision analysis, clustering, and portfolio problems.

During the 1980s and 1990s, six variants were proposed, handling with different models of outranking flows manipulation or approaches [43]: PROMETHEE I (partial outranking) [44]; PROMETHEE II (complete outranking) [44]; PROMETHEE III (complete outranking by intervals) [48]; PROMETHEE IV (continuous approach) [48]; PROMETHEE $\mathrm{V}$ (approach including segmentation constraints) [49]; and PROMETHEE VI (scenarios with uncertainty) [50]. Years later, a proposal intended for a group analysis was developed [51], enabling an evaluation in scenarios with multiple decision-makers.

Handling with fuzzy approaches [52-57], were developed some methods in search to support decision-making in scenarios where part of the information is unknown. Models based on method integration are also present [58-62], supporting the problem analysis by structuring the criteria or alternatives under a specific technique presented in a method and evaluating them by the PROMETHEE algorithm, enabling new modeling based.

Even the PROMETHEE method is commonly used to ranking problems, sorting and clustering approaches are present [63-67], working with proposals where the alternatives are allocated in clusters, ranking them into each class, or models where it is possible to obtain a partial or complete ranking of clusters. 


\subsection{SAPEVO-M Method}

The SAPEVO-M (Simple Aggregation of Preferences Expressed by Ordinal method Vectors-Multi Decision Makers), proposed by Gomes et al. [68], can be understood as an axiomatic evolution of the SAPEVO method [69], which introduced an evaluation for multiple decision-makers in the decision-making process, in addition to the axiomatic model previously developed, thus, bringing an increase in its consistency.

Utilizing ordinal scales transcribed by linguistics terms, it is possible to express an opinion regarding a variable [70], representing a relative value of importance and aggregating this information to cardinal data. As addressed by Gomes et al. [68], the main characteristic of the method is related to the ordinal transformation process of preferences, used to obtain the degrees of preference relations between the alternatives in each criterion, and also obtain the degrees of importance of the criteria, thus, generating their respective weights.

The axiomatic structure is based on a pairwise evaluation, aiming to express the respective preferences of the decision-maker. The ordinal evaluation is based on a scale of seven points $(-3,-2,-1,0,1,2,3)$, from absolutely worse to absolutely better, respectively, indicating the intensity of preference between the variables, alternatives, and criteria, providing cardinal preference through the punctuations obtained by $v=\left(\sum a_{i h}-\min a_{i h}\right) /\left(\max a_{i h}-\min a_{i h}\right)[68]$.

Once obtained, the respective cardinalities of the alternatives and criteria, representing their given relevance as to the preferences of the decision-makers, the values are set in an aggregation process, providing a global utility, indicating a final ranking of the alternatives. For a better understanding of the SAPEVO-M axiomatic process, please consult [68].

\subsection{The Proposed Approach}

The proposal represents the integration of two MCDA methods, PROMETHEE and SAPEVO-M. The approach PROMETHEE-SAPEVO-M1 allows a mono decision evaluation through a non-compensatory algorithm for ranking problems, considering quantitative and qualitative variables through cardinal and ordinal inputs, respectively.

Operating as a hybrid model, the model enables the evaluation of alternatives under qualitative and quantitative criteria, although if the problem presents only one type of nature, the analysis is still possible without the need to handle both natures, however, the presence of accurate and inaccurate information is common in most of decision-making cases [71]. The process structure of the proposal is designed in Figure 1, representing the steps that compose the modeling. Section 3 presents the axiomatic structure detail.

As approached in [72], a Decision Support System (DSS) provides a better decision analysis, in this way, and to support effective implementation of the new proposal, a web platform has been developed [73], in search to assist the understanding and application of the modeling, presenting a friendly interface by its numerical and graphical analysis. Moreover, the software was registered with the Brazilian National Institute of Industrial Property (INPI/BR). 


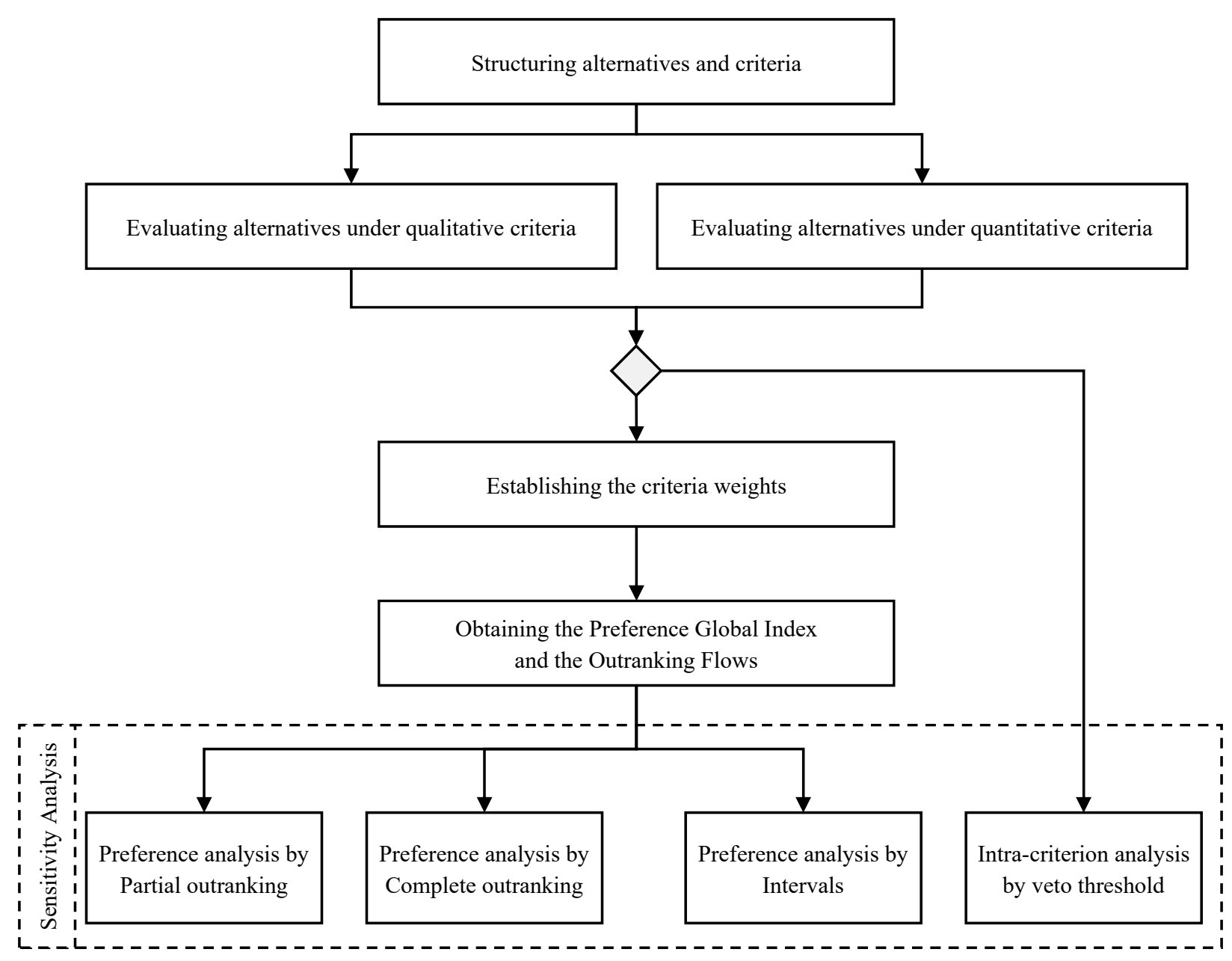

Figure 1. Steps of the modeling PROMETHEE-SAPEVO-M1.

\section{PROMETHEE-SAPEVO-M1}

As presented in Figure 1, the PROMETHEE-SAPEVO-M1 procedure is divided into five steps and some sub-steps: starting with the structure of the problem, followed by the evaluation of alternatives in each criterion according to its nature, then the criteria set is evaluated aiming to obtain the respective weights, finally, the global preferences index for each alternative is generated, providing the last step, characterized by the analysis of the results consisting in the integration of three preferences analysis model, along with an intra-criterion analysis.

\subsection{Problem Structuring}

Considering an evaluation matrix (Table 1), the problem is composed of an alternative set $\mathrm{A}$, where $a_{i} \in A, i=1, \ldots n$, evaluated under qualitative criteria set $\mathrm{H}$, where $c_{h} \in H, h=1, \ldots l$, and quantitative criteria set $\mathrm{J}$, where $g_{j} \in J, j=1, \ldots k$.

\subsection{Alternative Evaluation}

The alternatives performance evaluation is divided into two sub-steps, considering qualitative and quantitative data. Firstly, the alternatives under the qualitative criteria are performed, followed by the alternatives under the quantitative criteria.

\subsubsection{Evaluation under Qualitative Criteria}

Considering the set $H, c_{h} \in H, h=1, \ldots l$, a pairwise comparison analysis between the alternatives from set $A$ is realized. Using an ordinal scale composed of verbal expres- 
sions, as presented in Table 2, makes it possible to set a preference relation between a pair of alternatives regarding a qualitative criterion transcribed in numerical punctuation.

Table 1. Evaluation matrix, considering alternatives under qualitative and quantitative criteria.

\begin{tabular}{cccccc}
\hline $\boldsymbol{a}$ & $a_{\mathbf{1}}$ & $a_{\mathbf{2}}$ & $a_{\mathbf{3}}$ & $\ldots$ & $\boldsymbol{a}_{\boldsymbol{n}}$ \\
\hline$c_{h}$ & $a_{1 h}$ & $a_{2 h}$ & $a_{3 h}$ & $\ldots$ & $a_{n h}$ \\
$\vdots$ & $\vdots$ & $\vdots$ & $\vdots$ & $\ddots$ & $\vdots$ \\
$c_{l}$ & $a_{1 l}$ & $a_{2 l}$ & $a_{3 l}$ & $\ldots$ & $a_{n l}$ \\
$g_{j}$ & $a_{1 j}$ & $a_{2 j}$ & $a_{3 j}$ & $\ddots$ & $a_{n j}$ \\
$\vdots$ & $\vdots$ & $\vdots$ & $\vdots$ & $\ldots$ & $\vdots$ \\
$g_{k}$ & $a_{1 k}$ & $a_{2 k}$ & $a_{3 k}$ & $\ldots$ & $a_{n k}$ \\
\hline
\end{tabular}

Table 2. Ordinal scale of importance.

\begin{tabular}{cc}
\hline Verbal Expressions & Punctuation \\
\hline Absolutely worse/less important & -3 \\
Much worse/less important & -2 \\
Worst/less important & -1 \\
Equivalent & 0 \\
Best/more important & 1 \\
Much better/more important & 2 \\
Absolutely better/more important & 3 \\
\hline
\end{tabular}

For example, considering three alternatives, $a_{1}, a_{2}$, and $a_{3}$, as presented in Table 3. Between each pair of variables, is indicated a preference relation as exposed in Table 2, where the sum of preference of $a_{1}$ regarding $a_{2}$ and $a_{3}$, will represent the performance punctuation $\left(\sum a_{i h}\right)$ of alternative $a_{1}$ in a specific criterion.

Table 3. Example of qualitative comparison evaluation.

\begin{tabular}{ccccc}
\hline & $a_{1}$ & $a_{2}$ & $a_{3}$ & Punctuation \\
\hline$a_{1}$ & 0 & 2 & 1 & 3 \\
$a_{2}$ & -2 & 0 & -1 & -3 \\
$a_{3}$ & -1 & 1 & 0 & 0 \\
\hline
\end{tabular}

The sum of the punctuation of $a_{1}$ over the other alternatives from set $A$ is submitted to a normalization process by the Equation (1), enabling representing the relative importance of alternative $a_{1}$ in the criteria $c_{h}$. Based on Table 3 , the $\min a_{i h}=-3$ and $\max a_{i h}=3$.

$$
v=\frac{\sum a_{i h}-\min a_{i h}}{\max a_{i h}-\min a_{i h}}
$$

Based on the PROMETHEE procedure, the numerical values obtained for each alternative in $c_{h}$ are submitted to a maximization function, $d\left(a_{1}, a_{2}\right)=f\left(a_{1}\right)-\left(a_{2}\right)$, identifying the relative difference between a pair of alternatives. The process of qualitative evaluation ends normalizing the differences, using a linear function (2), and considering $p=1$, and generating a matrix representing the intensity of preference relationship [0,1] between each pair of alternatives, where:

- $\quad P_{h}\left(a_{1}, a_{2}\right)=0$, indicates no preference of $a_{1}$ over $a_{2}$;

- $\quad P_{h}\left(a_{1}, a_{2}\right) \cong 0$, indicates weak preference of $a_{1}$ over $a_{2}$;

- $\quad P_{h}\left(a_{1}, a_{2}\right) \cong 1$, indicates strong preference of $a_{1}$ over $a_{2}$;

- $\quad P_{h}\left(a_{1}, a_{2}\right)=1$, indicates strict preference of $a_{1}$ over $a_{2}$;

$$
P_{h}\left(a_{1}, a_{2}\right)=\left\{\begin{array}{c}
d / p d \leq p \\
1 d>p
\end{array}\right.
$$




\subsubsection{Evaluation under Quantitative Criteria}

To perform the alternatives under quantitative criteria $J$, where $g_{j} \in J, j=1, \ldots k$, the same PROMETHEE procedure is sustained. In each criterion, it is necessary to define if it is a relation of cost (minimization) or benefit (maximization), as explored in Section 2.1. The proposal keeps suggesting the six types of preference function (Figure 2) as presented in [44], where the preference function selected lies with the property of attribute [74].
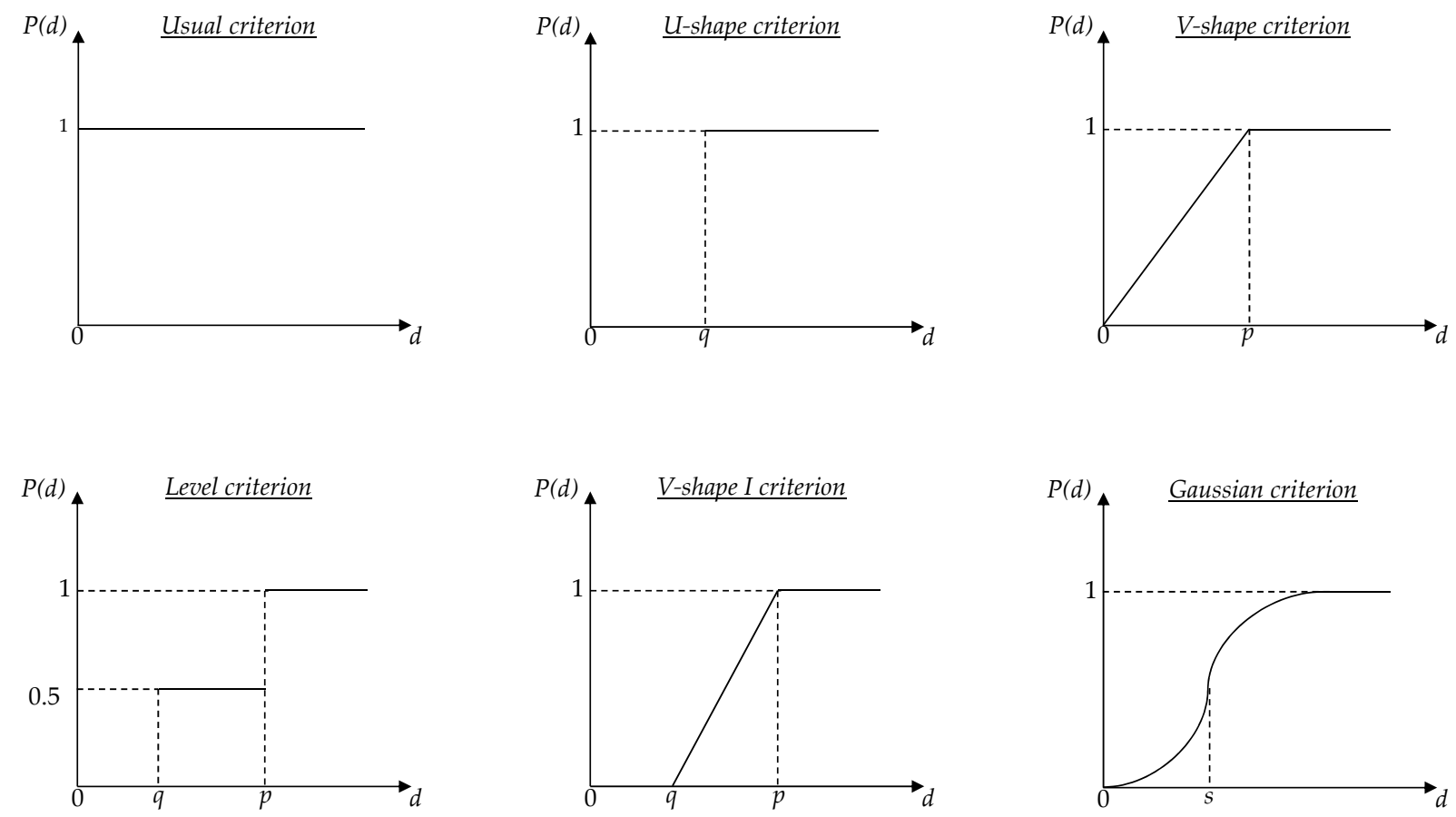

Figure 2. Six types of preference functions, adapted from [43].

According to each type of preference function selected to each criterion, it may be necessary to set some parameters, where usually three types of thresholds are used. As presented in [75], the parameter $q$ indicates a limit of indifference relation, where $P_{j}(d)=0$ if $d \leq q$, indicating that $a_{1} I a_{2}$; the parameter $p$ indicates a limit of strict preference, where $P_{j}(d)=1$ if $d \geq p$, indicating $a_{1} P a_{2}$; the parameter $s$, as the previous thresholds, indicates a superior relationship, the normalization is nonlinear with the attribute value difference $P_{j}(d)$, as presented in Gaussian function (Figure 2).

As aborded by Podvezko and Podviezko [76], the linear preference function V-shape I is the most valuable, and it is present in most theoretical and practical studies regarding the PROMETHEE methods. In this context, if the decision-maker is unsure about the attribution of values, the proposal suggests values that can be set for the parameters $q$ and $p$, enabling operating four from the six types of preference functions. Considering the obtained set of differences $P(d)_{j}$ in a quantitative criterion, it is suggested to set the parameter $q$ as the smallest value greater than zero, $q=\min P(d)_{j}>0$, and $p$ as the second smallest value greater than zero, $p=\min P(d)_{j}>q$, indicating strict preference for differences greater than the minimum in a specific criterion [77].

\subsection{Criteria Evaluation}

The evaluation of criteria considers qualitative and quantitative into only one set $C$, where $c_{j} \in C, j=1, \ldots l+k$. The performance is based on a pairwise comparison using the ordinal scale presented in Table 2, similar to the procedure aborded in Section 3.2.1, where each criterion will be compared to the other from set $C$, enabling to obtain a relation of importance of $c_{j}$ by the numerical punctuation obtained in $\sum c_{i j}$. The main difference of this process regards the maximum and minimum values of scales to normalization 
process of punctuation, where considering a mono decision evaluation, the proposal sets two values, named maximum sum (3) and minimum sum (4), both values represent the extremities of the scale where the scores obtained by each criterion will be allocated, as exposed in Figure 3, an example considering a set with three criteria.

$$
\begin{gathered}
\text { maxsum }=(n-1) 3 \\
\text { minsum }=(n-1)(-3)
\end{gathered}
$$

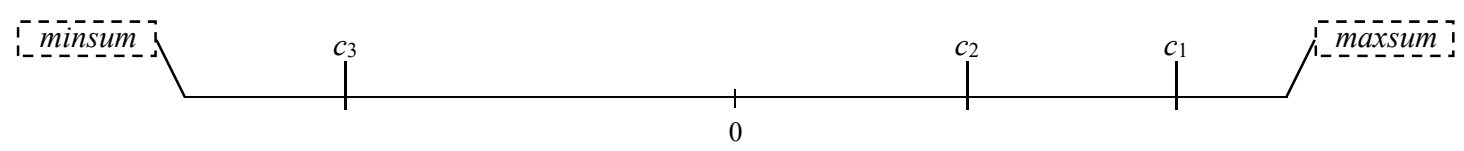

Figure 3. Performance of criteria into the scale considering the maximum sum and minimum sum.

Regarding the weights set, the closer a criterion score is to the maximum sum, the greater its dominance in the set will be; however, the lower the score is and the closer to the minimum sum, the criterion will represent a little importance in the set. The values obtained will be submitted to a normalization process (5), enabling to obtain the final weight (6) relative to each criterion, representing its respective importance in the set $C$. If a specific criterion obtains zero weight, $w\left(c_{j}\right)=0$, this criterion receives $1 \%$ from $x$, where $x=\min v\left(c_{j}\right)>0$.

$$
\begin{gathered}
v=\frac{\sum c_{i j}-\text { minsum }}{\text { maxsum }- \text { minsum }} \\
w\left(c_{j}\right)=\frac{v\left(c_{j}\right)}{\sum v\left(c_{j}\right)}
\end{gathered}
$$

\subsection{Preference Global Index}

Once obtained, the normalized matrices in each criterion and its respective weights, built by the decision-maker preferences, the Global Index $\pi\left(a_{1}, a_{2}\right)$ for each pairwise relation between the alternatives from set $A$ is generated. The index indicates the preference degree of $a_{1}$ over $a_{2}$ weighted according to the criteria preference set, where (7):

$$
\pi\left(a_{1}, a_{2}\right)=\sum_{j=1}^{k+l} P_{j}\left(a_{1}, a_{2}\right) w_{j}
$$

\subsection{Outranking Flows}

The obtained preference Global Index enables generating the outranking flows. The positive flow $\phi^{+}(8)$ represents how $a$ outranks the other alternatives $x$ in the set $A$, and the negative flow $\phi^{-}$(9) represents how $a$ is outranked by the other alternatives $x$. The higher the positive flow is and the lower the negative flow is, the better is the alternative [43]. Moreover, it is presented the net outranking flow $\phi(10)$ representing the difference between the positive and negative flows, providing a complete ranking.

$$
\begin{aligned}
\phi^{+}(a) & =\frac{1}{n-1} \sum_{x \in A} \pi(a, x) \\
\phi^{-}(a) & =\frac{1}{n-1} \sum_{x \in A} \pi(x, a) \\
\phi(a) & =\phi^{+}(a)-\phi^{-}(a)
\end{aligned}
$$

Based on the positive (1), negative (2), and net flows (3), the proposal works analyzing the results by three types of preference analysis, as partial outranking, complete outranking, and ranking by intervals, based on the PROMETHEE I, II, and III methods [37], respectively. 
The implementation of three models of results analysis provides a methodology that allows the decision-maker a sensitivity analysis, comparing the results, and brings gains for a robust evaluation, also integrated with an intra-criterion analysis.

\subsubsection{Partial Outranking}

Using the positive outranking, characterized by the global preference of $a_{1}$ over all other alternatives from the set $A$, and the negative outranking, represented by the preference of all alternatives over $a_{1}$, it is possible to obtain a partial ranking of alternatives. The evaluation is based on PROMETHEE I method, where the higher the positive flow is and the lower the negative flow is, the more favorable will be the alternative under evaluation, where (11)-(13):

- $a_{1}$ is preferable to $a_{2}\left(a_{1} P a_{2}\right)$ if $\left\{\begin{array}{l}\phi^{+}\left(a_{1}\right)>\phi^{+}\left(a_{2}\right) \text { and } \phi^{-}\left(a_{1}\right)<\phi^{-}\left(a_{2}\right) \text {, or } \\ \phi^{+}\left(a_{1}\right)=\phi^{+}\left(a_{2}\right) \text { and } \phi^{-}\left(a_{1}\right)<\phi^{-}\left(a_{2}\right) \text {, or } \\ \phi^{+}\left(a_{1}\right)>\phi^{+}\left(a_{2}\right) \text { and } \phi^{-}\left(a_{1}\right)=\phi^{-}\left(a_{2}\right) ;\end{array}\right.$

- $a_{1}$ is indifferent to $a_{2}\left(a_{1} I a_{2}\right)$ if $\phi^{+}\left(a_{1}\right)=\phi^{+}\left(a_{2}\right)$ and $\phi^{-}\left(a_{1}\right)=\phi^{-}\left(a_{2}\right)$;

- $a_{1}$ is incompatible to $a_{2}\left(a_{1} R a_{2}\right)$ if $\left\{\begin{array}{c}\phi^{+}\left(a_{1}\right)>\phi^{+}\left(a_{2}\right) \text { and } \phi^{-}\left(a_{1}\right)>\phi^{-}\left(a_{2}\right) \text {, or } \\ \phi^{+}\left(a_{1}\right)<\phi^{+}\left(a_{2}\right) \text { and } \phi^{-}\left(a_{1}\right)<\phi^{-}\left(a_{2}\right) \text {; }\end{array}\right.$

\subsubsection{Complete Outranking}

Based on the PROMETHEE II method, the analysis consists in the evaluation of the outranking net flows (10), providing relations of preference $P$ and indifference $I$, enabling a complete ranking. In this model of analysis, the higher the alternative net flow is, the better is the alternative in the context, where (14) and (15):

$$
\begin{aligned}
& \text { - } a_{1} \text { is preferable to } a_{2}\left(a_{1} P a_{2}\right) \text { if } \phi\left(a_{1}\right)>\phi\left(a_{2}\right) \\
& \text { - } a_{1} \text { is indifferent to } a_{2}\left(a_{1} I a_{2}\right) \text { if } \phi\left(a_{1}\right)=\phi\left(a_{2}\right)
\end{aligned}
$$

\subsubsection{Outranking by Intervals}

The third model of preference analysis, based on the PROMETHE III method, associates for each alternative $a_{1}$ an interval $\left[x_{a_{1}}, y_{a_{1}}\right]$, based on a standard error value (16), from the standard deviation of net outranking flows, where each interval is obtained by Equation (17). This model of analysis enables defining the complete ranking, where (18) and (19):

$$
\left.\begin{array}{c}
\alpha=\frac{\sigma}{\sqrt{n}} \\
\left\{\begin{array}{l}
x_{a_{1}}=\phi\left(a_{1}\right)-\alpha \\
y_{a_{1}}=\phi\left(a_{1}\right)+\alpha
\end{array}\right. \\
a_{1} \text { is preferable to } a_{2}\left(a_{1} P a_{2}\right) \text { if } x_{a_{1}}>y_{a_{2}}
\end{array}\right\}
$$

Simplifying, $\left[x_{a_{1}}, y_{a_{1}}\right]$ is an interval where the center is $\phi\left(a_{1}\right)$, and the length is proportional to the standard error, based on the distribution of the values $\pi\left(a_{1}, a_{2}\right)-\pi\left(a_{2}, a_{1}\right)$ [48] It is necessary to emphasize that the preference relation $P$ is transitive while the indifference relation $I$ remains intransitive. Exemplifying a practical application, Figure 4 exposes the preference relation between three alternatives $a_{1}, a_{2}$, and $a_{3}$, where $a_{1} I a_{2}$ and $a_{2} I a_{3}$, but $a_{1}$ remains preferable to $a_{3}\left(a_{1} P a_{3}\right)$.

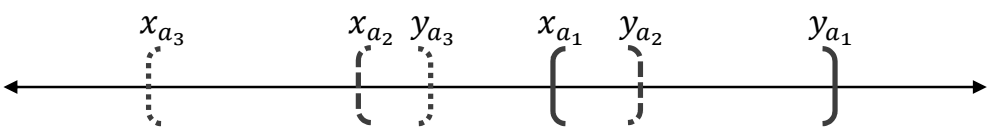

Figure 4. Relation of preference between intervals, adapted from [48]. 


\subsubsection{Intra-Criterion Analysis by Veto}

As aborded in [78], for a robust and complete analysis of a problem, along with a global evaluation, an intra-criterion analysis should be conducted, recognizing the performance of alternatives in each specific criterion.

In this step, for each criterion evaluated, qualitative and quantitative, a veto threshold $v_{j}$ is suggested. As presented in Figure 1, this analysis does not influence and is not influenced regarding the outranking flows; however, the veto works as additional information to the decision-making process, sustaining the restriction that the veto must be greater than or equal to the parameter of preference and indifference, where $v_{j} \geq p_{j} \geq q_{j}$.

The intra-criterion analysis by veto threshold suggests an equivalence between alternatives with low performance $\left(a_{x}\right)$ and high performance $\left(a_{y}\right)$ in the global context, from the moment that $a_{x}$ presents a strict preference over $a_{y}$ in a specific criterion $c_{j}$. About qualitative criteria, $v_{h}=1$, and works regarding the normalized matrices obtained in the performance of alternatives in $c_{h}$, explored in Section 3.2.1. Concerning quantitative criterion, the veto works regarding the matrices of difference obtained by the pairwise comparison, using generalized functions of cost or benefit, in this case, $v_{j}=\max \left(a_{i j}\right)$, if in criterion $g_{j}$ a preference threshold $p$ be set, and $p>v_{j}$, the veto value becomes equivalent to preference $v_{j}=p$, and there is no veto indication in this criterion.

\section{Case Study}

Based on a strategic decision-making process of $\mathrm{BN}$ in acquiring new attack helicopters to support its operations, a multi-criteria evaluation by the PROMETHEE-SAPEVO-M1 modeling is carried out. To make the present study feasible, providing analysis as close as possible to the reality, we used the support of stakeholders present in tactical and strategic combat operations concerning the employment of helicopters of attack. For this evaluation, three officers of the Brazilian navy were consulted, one being a combat operations commander and two aviators.

The alternatives chosen are among the most used helicopter models in the armed forces worldwide, with recognized effectiveness in military missions. In the sequence, all helicopters under analysis are described:

- $\quad$ AH-1Z VIPER (BELL): Built to meet the needs of the United States Marine Corps (USMC), being used by this force since 2009. Due to the USMC operating in various environments, mainly at sea, this aircraft has been specially developed to withstand the maritime weather [79];

- $\quad$ T129 ATAK (Turkish Aerospace): Manufactured by Turkish Aerospace, the T129 ATAK was developed to meet the needs of the Turkish Armed Forces. It is a twin-engine attack helicopter, optimized for carrying out attack missions, armed reconnaissance, and precision attacks under various weather conditions and during day and night periods [80];

- Mi-35M (Russian Helicopters): Currently manufactured by Russian Helicopters and primarily developed by Mil Moscow Helicopter Plant, it is an attack helicopter that has its size as a differential, as it has relatively higher weight and dimensions than an ordinary attack helicopter [81];

- Ka-52K Katran (Russian Helicopters): Version designed to operate in the naval environment of the Ka-52 Alligator, produced by Russian Helicopters. It is a state-of-the-art reconnaissance and combat aircraft aiming to destroy armored and unarmored ground targets, troops, and enemy helicopters on both the front line and tactical reserves [81];

- Tiger HAD (Airbus): A multifunctional attack helicopter, which aims to conduct armed reconnaissance, air-to-ground escorts, air-to-air combat, air-to-air support, and attacks on armored targets on land, day or night and in harsh conditions [82];

- AH-64E APACHE (Boeing): One of the world's best-known attack helicopters, the AH-64E APACHE, produced by Boeing, is widely employed by several armed forces, such as the United States Army, Egypt, Greece, India, Indonesia, Israel, Japan, Korea, 
Kuwait, the Netherlands, Qatar, Saudi Arabia, Singapore, the United Arab Emirates, and the United Kingdom [83];

- $\quad$ Sikorsky S-70 (SIKORSKY): It is a helicopter capable of operating anywhere on the globe, whether in cold or high-temperature regions, thanks to its configuration and power reserve. Its essential mission is troop transport. Containing equipment that allows performing the flight by instruments, this aircraft is configured to enable the flight with night vision goggles [11];

- H215M (Airbus): Operated by the Brazilian Army, it is fit for employment in combat missions, combat support, and logistical support. It has several optional equipment and accessories, including 4.5-ton hooks, a $272 \mathrm{~kg}$ winch engine, and six stretchers for aeromedical evacuation [11];

- H160M (Airbus): This helicopter can be reconfigured in a fast way to perform missions ranging from commando infiltration to air intercept, fire support, and anti-ship warfare; up to two stretchers for search and rescue operations; as well as a fast rope system, cargo hook, and hoist, that is used equally for public missions-a versatile, all-in-one asset for modern militaries [84].

The helicopters were evaluated in light of operational and tactical criteria. It is fundamental to highlight that, after consultation with the officers and helicopter manuals, quantitative and qualitative criteria were considered relevant for the proposed analysis. In this context, the PROMETHEE-SAPEVO-M1 modeling was chosen as the tool to support decision-making, allowing an integrated algorithm and enabling to perform qualitative and quantitative data, providing the structuring and analysis of variables where it is not possible to define a precise numerical input. Regarding the analysis, fourteen criteria were considered in this assessment:

- Technological level: Aggregate technology of the aircraft, concerning radars, sensors, safety devices in flight, increasing efficiency and noise reduction;

- Main Cannon system: A weapon widely used in close combat, consisting of aerial actions by fixed-wing and rotating aircraft against hostile targets that are close to friendly forces. This component can be used against ground troops, vehicles, buildings, or even hostile aircraft. This study will compare the aggregate technology, robustness, reliability, and destructive power of helicopter cannon systems;

- Missiles System: The missiles have great power of destruction and are usually laserguided against armored vehicles, buildings, and other types of targets. However, due to their larger size, they are transported in smaller numbers than rockets in combat aircraft. In this criterion, the accuracy and firepower of missiles of each helicopter will be compared;

- Weapons subsystems: In this criterion, the combat control systems of each helicopter are evaluated, concerning the integration between sensors, components, and flexible armaments such as machine guns;

- Armor level: Sheet metal coating (such as steel or another resistant alloy) to protect the aircraft from projectiles, combat devices, or electrical discharge from lightning;

- Employment flexibility: Capability to use the aircraft in activities beyond combat, such as aeromedical evacuations and other logistics operations;

- Maximum Speed: Speed developed with the maximum engine regime, essential for reconnaissance, interception, and fire support to troops in critical situations;

- Cruising speed: Operating speed at which combustion engines have an optimum efficiency level for fuel consumption and power output;

- Range: Whereas a theater of operations may have large dimensions, the greater the range of an aircraft, the greater the capacity to operate in different missions;

- Autonomy: Maximum time that an aircraft can spend in cruising flight. In other words, it is how long an aircraft can stay on-air with one load of fuel;

- Service ceiling: Maximum usable altitude of an aircraft;

- Maximum Payload: Measure obtained by reducing the weight of the aircraft from the maximum take-off weight of the helicopter. Such a measure is relevant because it will 
directly influence the range, quantity of fuel, and ammunition/armament that the helicopter will be able to carry;

- Troop Capacity: Maximum number of passengers transported in addition to aircraft pilots;

- Length: Distance from the bow (front) to the stern (reverse part) of the helicopter. Considering that some regions often present difficult maneuverability, it is sought the minimum value for this criterion. Therefore, the shorter the length, the better.

\subsection{Numerical Implementation}

The analyzed problem handles the priory to rank and identifies a favorable alternative regarding the employment of attack helicopters in $\mathrm{BN}$ naval operations. Considering the set of variables, nine alternatives were evaluated under fourteen criteria, being six qualitative and eight quantitative. Table 4 details the evaluation matrix, exposing the performance of the alternatives in each criterion. The qualitative performance, expressed by verbal terms, is clarified in the following procedures.

Table 4. Evaluation matrix regarding the helicopters under qualitative and quantitative criteria.

\begin{tabular}{|c|c|c|c|c|c|c|c|c|c|}
\hline & $\begin{array}{c}\text { T129 } \\
\text { ATAK }\end{array}$ & MI-35M & VIPER & Katran & $\begin{array}{l}\text { Tiger } \\
\text { HAD }\end{array}$ & APACHE & $\begin{array}{c}\text { Sikorsky } \\
\text { S-70 }\end{array}$ & H215M & H160M \\
\hline Technological level & Advanced & Proficient & Advanced & Advanced & Advanced & Advanced & Proficient & Basic & Advanced \\
\hline Main cannon system & Proficient & Proficient & Proficient & Advanced & Advanced & $\begin{array}{l}\text { High Ad- } \\
\text { vanced }\end{array}$ & Proficient & Basic & Basic \\
\hline Missiles system & Proficient & Advanced & Advanced & Advanced & Proficient & Advanced & Proficient & Basic & Basic \\
\hline Armament subsystems & Advanced & Proficient & Advanced & Advanced & Advanced & Advanced & Proficient & Basic & Basic \\
\hline Armor level & $\begin{array}{l}\text { High Ad- } \\
\text { vanced }\end{array}$ & Advanced & Advanced & Advanced & $\begin{array}{c}\text { High Ad- } \\
\text { vanced }\end{array}$ & $\begin{array}{l}\text { High Ad- } \\
\text { vanced }\end{array}$ & Proficient & Proficient & Proficient \\
\hline Employment flexibility & Good & Good & Good & Good & Average & Good & Average & Average & $\begin{array}{l}\text { Very } \\
\text { Good }\end{array}$ \\
\hline $\begin{array}{l}\text { Maximum speed } \\
(\mathrm{Km} / \mathrm{h})\end{array}$ & 281 & 310 & 370 & 300 & 271 & 279 & 315 & 278 & 325 \\
\hline Cruising speed $(\mathrm{Km} / \mathrm{h})$ & 269 & 240 & 257 & 260 & 230 & 269 & 223 & 258 & 255 \\
\hline Range $(\mathrm{Km})$ & 537 & 460 & 485 & 460 & 740 & 476 & 450 & 780 & 848 \\
\hline Autonomy (h) & 3 & 3.5 & 3.5 & 3.5 & 2.7 & 3 & 3 & 3.9 & 4.5 \\
\hline Service ceiling (m) & 6096 & 5400 & 6000 & 5500 & 4000 & 6096 & 5837 & 3450 & 5900 \\
\hline Maximum payload $(\mathrm{Kg})$ & 2710 & 2400 & 2615 & 3300 & 2030 & 2835 & 4045 & 3000 & 1500 \\
\hline Troop capacity $(\mathrm{Qt})$ & 0 & 8 & 0 & 0 & 0 & 0 & 13 & 20 & 12 \\
\hline Length $(\mathrm{m})$ & 13.64 & 21.6 & 17.8 & 16 & 13.85 & 14.68 & 15.26 & 15.5 & 14 \\
\hline
\end{tabular}

The proposed approach starts evaluating the alternatives regarding the qualitative criteria: Technological level, Main cannon system, Missiles system, Armament subsystems, Armor level, and Employment flexibility. The consulted officers exposed their opinions, providing the preference punctuation between alternatives. In each qualitative criterion, is presented the preference relation between each pair of alternatives, providing the cardinal punctuations of alternatives in the analysis, as exposed in the following Tables 5-10.

Regarding the evaluation of alternatives setting the preferences by ordinal scale, it was possible to obtain cardinal punctuation to each alternative in a qualitative criterion. As exposed in Section 3.2.1, the alternative punctuations are submitted in a maximization process in search to obtain the difference between each pair and convert it in a final preference index of each pair of alternatives in each criterion, represented by a matrix.

Following the modeling procedure, the alternatives are evaluated under the quantitative criteria, sustaining the process of the PROMETHEE method. It was defined, for each quantitative criterion, if it is a criterion of benefit (maximization) or cost (minimization), and which type of preference function (Figure 2) is suitable to provide the final preference degree. Table 11 presents all information regarding the necessary data for quantitative evaluation, highlighting the use of the preference functions $V$-shape and $V$-shape $I$. The selected preference functions enabled to perform the alternatives concerning the limits of indifference $(q)$ and preference $(p)$, providing relations of non-preference, linear preference, and strict preference. 
Table 5. Evaluation of alternatives under qualitative criterion Technological level.

\begin{tabular}{cccccccccccc}
\hline $\begin{array}{c}\text { Technological } \\
\text { Level }\end{array}$ & T129 & MTAK & 35M & VIPER & Katran & $\begin{array}{c}\text { Tiger } \\
\text { HAD }\end{array}$ & APACHE & $\begin{array}{c}\text { Sikorsky } \\
\text { S-70 }\end{array}$ & H215M & H160M & $\begin{array}{c}\text { Punctuation } \\
\text { Pormalized } \\
\text { Punctuation }\end{array}$ \\
\hline T129 ATAK & 0 & 1 & 0 & 0 & 0 & 0 & 1 & 2 & 0 & 4 & 0.905 \\
MI-35M & -1 & 0 & -1 & -1 & -1 & -1 & 0 & 1 & -1 & -5 & 0.476 \\
VIPER & 0 & 1 & 0 & 0 & 1 & 0 & 1 & 3 & 0 & 6 & 1 \\
Katran & 0 & 1 & 0 & 0 & 0 & 0 & 1 & 2 & 0 & 4 & 0.905 \\
Tiger HAD & 0 & 1 & -1 & 0 & 0 & 0 & 1 & 2 & 0 & 3 & 0.857 \\
APACHE & 0 & 1 & 0 & 0 & 0 & 0 & 1 & 2 & 0 & 4 & 0.905 \\
Sikorsky S-70 & -1 & 0 & -1 & -1 & -1 & -1 & 0 & 1 & -1 & -5 & 0.476 \\
H215M & -2 & -1 & -3 & -2 & -2 & -2 & -1 & 0 & -2 & -15 & 0 \\
H160M & 0 & 1 & 0 & 0 & 0 & 0 & 1 & 2 & 0 & 4 & 0.905 \\
\hline
\end{tabular}

Table 6. Evaluation of alternatives under qualitative criterion Main cannon system.

\begin{tabular}{|c|c|c|c|c|c|c|c|c|c|c|c|}
\hline $\begin{array}{c}\text { Main Cannon } \\
\text { System }\end{array}$ & $\begin{array}{c}\text { T129 } \\
\text { ATAK }\end{array}$ & $\begin{array}{l}\text { MI- } \\
35 \mathrm{M}\end{array}$ & VIPER & Katran & $\begin{array}{l}\text { Tiger } \\
\text { HAD }\end{array}$ & APACHE & $\begin{array}{l}\text { Sikorsky } \\
\text { S-70 }\end{array}$ & H215M & H160M & Punctuation & $\begin{array}{l}\text { Normalized } \\
\text { Punctuation }\end{array}$ \\
\hline T129 ATAK & 0 & 0 & 0 & -1 & -1 & -2 & 0 & 1 & 1 & -2 & 0.333 \\
\hline MI-35M & 0 & 0 & 0 & -1 & -1 & -2 & 0 & 1 & 1 & -2 & 0.333 \\
\hline VIPER & 0 & 0 & 0 & -1 & -1 & -2 & 0 & 1 & 1 & -2 & 0.333 \\
\hline Katran & 1 & 1 & 1 & 0 & 0 & -1 & 1 & 2 & 2 & 7 & 0.667 \\
\hline Tiger HAD & 1 & 1 & 1 & 0 & 0 & -1 & 1 & 2 & 2 & 7 & 0.667 \\
\hline APACHE & 2 & 2 & 2 & 1 & 1 & 0 & 2 & 3 & 3 & 16 & 1 \\
\hline Sikorsky S-70 & 0 & 0 & 0 & -1 & -1 & -2 & 0 & 1 & 1 & -2 & 0.333 \\
\hline H215M & -1 & -1 & -1 & -2 & -2 & -3 & -1 & 0 & 0 & -11 & 0 \\
\hline H160M & -1 & -1 & -1 & -2 & -2 & -3 & -1 & 0 & 0 & -11 & 0 \\
\hline
\end{tabular}

Table 7. Evaluation of alternatives under qualitative criterion Missiles system.

\begin{tabular}{|c|c|c|c|c|c|c|c|c|c|c|c|}
\hline $\begin{array}{c}\text { Missiles } \\
\text { System }\end{array}$ & $\begin{array}{c}\text { T129 } \\
\text { ATAK }\end{array}$ & $\begin{array}{l}\text { MI- } \\
35 \mathrm{M}\end{array}$ & VIPER & Katran & $\begin{array}{l}\text { Tiger } \\
\text { HAD }\end{array}$ & APACHE & $\begin{array}{l}\text { Sikorsky } \\
\text { S-70 }\end{array}$ & H215M & H160M & Punctuation & $\begin{array}{l}\text { Normalized } \\
\text { Punctuation }\end{array}$ \\
\hline T129 ATAK & 0 & -1 & -1 & -1 & 0 & -1 & 0 & 1 & 1 & -2 & 0.5 \\
\hline MI-35M & 1 & 0 & 0 & 0 & 1 & 0 & 1 & 2 & 2 & 7 & 1 \\
\hline VIPER & 1 & 0 & 0 & 0 & 1 & 0 & 1 & 2 & 2 & 7 & 1 \\
\hline Katran & 1 & 0 & 0 & 0 & 1 & 0 & 1 & 2 & 2 & 7 & 1 \\
\hline Tiger HAD & 0 & -1 & -1 & -1 & 0 & -1 & 0 & 1 & 1 & -2 & 0.5 \\
\hline APACHE & 1 & 0 & 0 & 0 & 1 & 0 & 1 & 2 & 2 & 7 & 1 \\
\hline Sikorsky S-70 & 0 & -1 & -1 & -1 & 0 & -1 & 0 & 1 & 1 & -2 & 0.5 \\
\hline H215M & -1 & -2 & -2 & -2 & -1 & -2 & -1 & 0 & 0 & -11 & 0 \\
\hline H160M & -1 & -2 & -2 & -2 & -1 & -2 & -1 & 0 & 0 & -11 & 0 \\
\hline
\end{tabular}

Table 8. Evaluation of alternatives under qualitative criterion Armament subsystems.

\begin{tabular}{cccccccccccc}
\hline $\begin{array}{c}\text { Armament } \\
\text { Subsystems }\end{array}$ & T129 & MTAK & M5M & VIPER & Katran & $\begin{array}{c}\text { Tiger } \\
\text { HAD }\end{array}$ & APACHE & $\begin{array}{c}\text { Sikorsky } \\
\text { S-70 }\end{array}$ & H215M & H160M & $\begin{array}{c}\text { Punctuation } \\
\text { Pormalized } \\
\text { Punctuation }\end{array}$ \\
\hline T129 ATAK & 0 & 1 & 0 & 0 & 0 & 0 & 1 & 2 & 2 & 6 \\
MI-35M & -1 & 0 & -1 & -1 & -1 & -1 & 0 & 1 & 1 & -3 & 0.5 \\
IIPER & 0 & 1 & 0 & 0 & 0 & 0 & 1 & 2 & 2 & 6 & 1 \\
Katran & 0 & 1 & 0 & 0 & 0 & 0 & 1 & 2 & 2 & 6 & 1 \\
Tiger HAD & 0 & 1 & 0 & 0 & 0 & 0 & 1 & 2 & 2 & 6 & 6 \\
APACHE & 0 & 1 & 0 & 0 & 0 & 0 & 1 & 2 & 2 & 1 \\
Sikorsky S-70 & -1 & 0 & -1 & -1 & -1 & -1 & 0 & 1 & 1 & -3 & 0.5 \\
H215M & -2 & -1 & -2 & -2 & -2 & -2 & -1 & 0 & 0 & -12 & 0 \\
H160M & -2 & -1 & -2 & -2 & -2 & -2 & -1 & 0 & 0 & -12 & 0 \\
\hline
\end{tabular}


Table 9. Evaluation of alternatives under qualitative criterion Armor.

\begin{tabular}{|c|c|c|c|c|c|c|c|c|c|c|c|}
\hline Armor Level & $\begin{array}{c}\text { T129 } \\
\text { ATAK }\end{array}$ & $\begin{array}{l}\text { MI- } \\
35 \mathrm{M}\end{array}$ & VIPER & Katran & $\begin{array}{l}\text { Tiger } \\
\text { HAD }\end{array}$ & APACHE & $\begin{array}{l}\text { Sikorsky } \\
\text { S-70 }\end{array}$ & H215M & H160M & Punctuation & $\begin{array}{l}\text { Normalized } \\
\text { Punctuation }\end{array}$ \\
\hline T129 ATAK & 0 & 1 & 1 & 1 & 0 & 0 & 2 & 2 & 2 & 9 & 1 \\
\hline MI-35M & -1 & 0 & 0 & 0 & -1 & -1 & 1 & 1 & 1 & 0 & 0.5 \\
\hline VIPER & -1 & 0 & 0 & 0 & -1 & -1 & 1 & 1 & 1 & 0 & 0.5 \\
\hline Katran & -1 & 0 & 0 & 0 & -1 & -1 & 1 & 1 & 1 & 0 & 0.5 \\
\hline Tiger HAD & 0 & 1 & 1 & 1 & 0 & 0 & 2 & 2 & 2 & 9 & 1 \\
\hline APACHE & 0 & 1 & 1 & 1 & 0 & 0 & 2 & 2 & 2 & 9 & 1 \\
\hline Sikorsky S-70 & -2 & -1 & -1 & -1 & -2 & -2 & 0 & 0 & 0 & -9 & 0 \\
\hline $\mathrm{H} 215 \mathrm{M}$ & -2 & -1 & -1 & -1 & -2 & -2 & 0 & 0 & 0 & -9 & 0 \\
\hline H160M & -2 & -1 & -1 & -1 & -2 & -2 & 0 & 0 & 0 & -9 & 0 \\
\hline
\end{tabular}

Table 10. Evaluation of alternatives under qualitative criterion Employment flexibility.

\begin{tabular}{|c|c|c|c|c|c|c|c|c|c|c|c|}
\hline $\begin{array}{l}\text { Employment } \\
\text { Flexibility }\end{array}$ & $\begin{array}{c}\text { T129 } \\
\text { ATAK }\end{array}$ & $\begin{array}{l}\text { MI- } \\
35 \mathrm{M}\end{array}$ & VIPER & Katran & $\begin{array}{l}\text { Tiger } \\
\text { HAD }\end{array}$ & APACHE & $\begin{array}{l}\text { Sikorsky } \\
\text { S-70 }\end{array}$ & H215M & H160M & Punctuation & $\begin{array}{l}\text { Normalized } \\
\text { Punctuation }\end{array}$ \\
\hline T129 ATAK & 0 & 0 & 0 & 0 & 1 & 0 & 1 & 1 & -1 & 2 & 0.5 \\
\hline MI-35M & 0 & 0 & 0 & 0 & 1 & 0 & 1 & 1 & -1 & 2 & 0.5 \\
\hline VIPER & 0 & 0 & 0 & 0 & 1 & 0 & 1 & 1 & -1 & 2 & 0.5 \\
\hline Katran & 0 & 0 & 0 & 0 & 1 & 0 & 1 & 1 & -1 & 2 & 0.5 \\
\hline Tiger HAD & -1 & -1 & -1 & -1 & 0 & -1 & 0 & 0 & -2 & -7 & 0 \\
\hline APACHE & 0 & 0 & 0 & 0 & 1 & 0 & 1 & 1 & -1 & 2 & 0.5 \\
\hline Sikorsky S-70 & -1 & -1 & -1 & -1 & 0 & -1 & 0 & 0 & -2 & -7 & 0 \\
\hline H215M & -1 & -1 & -1 & -1 & 0 & -1 & 0 & 0 & -2 & -7 & 0 \\
\hline H160M & 1 & 1 & 1 & 1 & 2 & 1 & 2 & 2 & 0 & 11 & 1 \\
\hline
\end{tabular}

Table 11. Preference function and thresholds.

\begin{tabular}{clccc}
\hline & $\begin{array}{c}\text { Generalized } \\
\text { Function }\end{array}$ & $\begin{array}{c}\text { Preference } \\
\text { Function }\end{array}$ & $\begin{array}{c}\text { Indifference } \\
\text { Threshold }(\boldsymbol{q})\end{array}$ & $\begin{array}{c}\text { Preference } \\
\text { Threshold }(\boldsymbol{p})\end{array}$ \\
\hline Maximum speed $(\mathrm{Km} / \mathrm{h})$ & Maximization & V-shape & - & 50 \\
Cruising speed $(\mathrm{Km} / \mathrm{h})$ & Maximization & V-shape & - & 40 \\
Range $(\mathrm{Km})$ & Maximization & V-shape I & 50 & 200 \\
Autonomy $(\mathrm{h})$ & Maximization & V-shape I & 0.5 & 2 \\
Service ceiling $(\mathrm{m})$ & Maximization & V-shape I & 200 & 1000 \\
Maximum payload $(\mathrm{Kg})$ & Maximization & V-shape & - & 1000 \\
Troop capacity $(\mathrm{Qt})$ & Maximization & V-shape I & 2 & 5 \\
Length $(\mathrm{m})$ & Minimization & V-shape I & 1 & 4 \\
\hline
\end{tabular}

It is noteworthy that the V-shape and V-shape I functions are used to enable a preference limit, that is, any alternative above this limit presents a strict preference as to another within the specific criterion, and also for providing to identify a linear performance at least that it is, for example, when analyzing the speed of the helicopters.

Having obtained all preference degrees between the alternatives in each criterion, it is necessary to evaluate the criteria set in search to obtain their respective weights. Table 12 presents the ordinal inputs between each pair of criteria, along with their punctuation, normalized punctuations, and final weights obtained based on maximum sum and minimum sum variables.

Once the weights of criteria are established, the preference degrees from qualitative and quantitative evaluations are weighted. Then, is generated the global preference index between each pair of alternatives, representing the degree of dominance of each helicopter over the others in the set, as presented in Table 13. Through these indexes, is obtained the positive, negative, and net outranking flow. Thus, these flows will serve as a basis for the construction of the three models of results analysis. 
Table 12. Importance relation between criteria and weights obtained.

\begin{tabular}{|c|c|c|c|c|c|c|c|c|c|c|c|c|c|c|c|c|c|c|c|c|}
\hline & \multirow{2}{*}{ 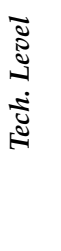 } & \multirow{2}{*}{ 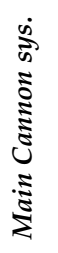 } & \multirow{2}{*}{$\begin{array}{l}\dot{s} \\
\vec{n} \\
\tilde{y} \\
\frac{\tilde{U}}{\tilde{D}} \\
\stackrel{2}{z}\end{array}$} & \multirow{2}{*}{ 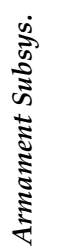 } & \multirow{2}{*}{ 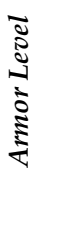 } & \multirow{2}{*}{ 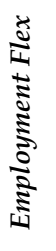 } & \multirow{2}{*}{ 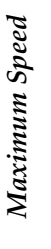 } & \multirow{2}{*}{ 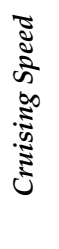 } & \multirow[t]{2}{*}{$\underset{\Sigma}{\mathbb{\Xi}}$} & \multirow{2}{*}{ 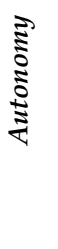 } & \multirow{2}{*}{ 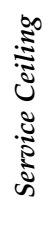 } & \multirow{2}{*}{ 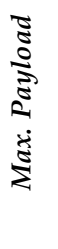 } & \multirow{2}{*}{ 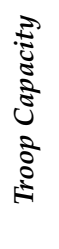 } & \multirow[t]{2}{*}{ 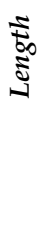 } & & \multicolumn{5}{|c|}{$\begin{array}{c}\text { Maximum sum }=39 \\
\text { Minimum } \text { sum }=-39\end{array}$} \\
\hline & & & & & & & & & & & & & & & & Punctuation & & $\begin{array}{l}\text { Normalized } \\
\text { Punctuation }\end{array}$ & & $\begin{array}{c}\text { Final } \\
\text { Weights }\end{array}$ \\
\hline Tech. level & 0 & -1 & -1 & -1 & -1 & 2 & 1 & 0 & 1 & 1 & 3 & -1 & 2 & 3 & $=$ & 8 & $=$ & 0.603 & $=$ & 0.086 \\
\hline Main cannon sys. & 1 & 0 & 0 & 0 & 0 & 3 & 2 & 1 & 2 & 2 & 3 & 0 & 3 & 3 & $=$ & 20 & $=$ & 0.756 & $=$ & 0.108 \\
\hline Missiles sys. & 1 & 0 & 0 & 0 & 0 & 3 & 2 & 1 & 2 & 2 & 3 & 0 & 3 & 3 & $=$ & 20 & $=$ & 0.756 & $=$ & 0.108 \\
\hline Armament subsys. & 1 & 0 & 0 & 0 & 0 & 3 & 2 & 1 & 2 & 2 & 3 & 0 & 3 & 3 & $=$ & 20 & $=$ & 0.756 & $=$ & 0.108 \\
\hline Armor level & 1 & 0 & 0 & 0 & 0 & 3 & 2 & 1 & 2 & 2 & 3 & 0 & 3 & 3 & $=$ & 20 & $=$ & 0.756 & $=$ & 0.108 \\
\hline Employment flex. & -2 & -3 & -3 & -3 & -3 & 0 & -1 & -2 & -1 & -1 & 1 & -3 & 0 & 1 & $=$ & -20 & $=$ & 0.244 & $=$ & 0.035 \\
\hline Maximum speed & -1 & -2 & -2 & -2 & -2 & 1 & 0 & -1 & 0 & 0 & 2 & -2 & 1 & 2 & $=$ & -6 & $=$ & 0.423 & $=$ & 0.060 \\
\hline Cruising speed & 0 & -1 & -1 & -1 & -1 & 2 & 1 & 0 & 1 & 1 & 3 & -1 & 2 & 3 & $=$ & 8 & $=$ & 0.603 & $=$ & 0.086 \\
\hline Range & -1 & -2 & -2 & -2 & -2 & 1 & 0 & -1 & 0 & 0 & 2 & -2 & 1 & 2 & $=$ & -6 & $=$ & 0.423 & $=$ & 0.060 \\
\hline Autonomy & -1 & -2 & -2 & -2 & -2 & 1 & 0 & -1 & 0 & 0 & 2 & -2 & 1 & 2 & $=$ & -6 & $=$ & 0.423 & $=$ & 0.060 \\
\hline Service ceiling & -3 & -3 & -3 & -3 & -3 & -1 & -2 & -3 & -2 & -2 & 0 & -3 & -1 & 0 & $=$ & -29 & $=$ & 0.128 & $=$ & 0.018 \\
\hline Max. payload & 1 & 0 & 0 & 0 & 0 & 3 & 2 & 1 & 2 & 2 & 3 & 0 & 3 & 3 & $=$ & 20 & $=$ & 0.756 & $=$ & 0.108 \\
\hline Troop capacity & -2 & -3 & -3 & -3 & -3 & 0 & -1 & -2 & -1 & -1 & 1 & -3 & 0 & 1 & $=$ & -20 & $=$ & 0.244 & $=$ & 0.035 \\
\hline Length & -3 & -3 & -3 & -3 & -3 & -1 & -2 & -3 & -2 & -2 & 0 & -3 & -1 & 0 & $=$ & -29 & $=$ & 0.128 & $=$ & 0.018 \\
\hline
\end{tabular}

Table 13. Global Index of preference along with the outranking flows.

\begin{tabular}{|c|c|c|c|c|c|c|c|c|c|c|c|}
\hline & $\begin{array}{c}\text { T129 } \\
\text { ATAK }\end{array}$ & MI-35M & VIPER & Katran & $\begin{array}{l}\text { Tiger } \\
\text { HAD }\end{array}$ & APACHE & $\begin{array}{c}\text { Sikorsky } \\
\text { S-70 }\end{array}$ & H215M & H160M & $\phi^{+}$ & $\phi$ \\
\hline $\begin{array}{c}\text { T129 } \\
\text { ATAK }\end{array}$ & 0 & 0.020 & 0.008 & 0.007 & 0.015 & 0 & 0.023 & 0.032 & 0.032 & 0.137 & 0.051 \\
\hline MI-35M & 0.009 & 0 & 0.003 & 0.003 & 0.017 & 0.005 & 0.012 & 0.026 & 0.025 & 0.100 & -0.044 \\
\hline VIPER & 0.009 & 0.017 & 0 & 0.005 & 0.021 & 0.005 & 0.026 & 0.035 & 0.034 & 0.152 & 0.074 \\
\hline Katran & 0.013 & 0.020 & 0.009 & 0 & 0.022 & 0.005 & 0.024 & 0.037 & 0.033 & 0.163 & 0.101 \\
\hline Tiger HAD & 0.007 & 0.018 & 0.012 & 0.009 & 0 & 0.004 & 0.022 & 0.031 & 0.028 & 0.131 & -0.018 \\
\hline APACHE & 0.010 & 0.025 & 0.013 & 0.009 & 0.022 & 0 & 0.031 & 0.041 & 0.041 & 0.192 & 0.136 \\
\hline $\begin{array}{c}\text { Sikorsky } \\
\text { S-70 }\end{array}$ & 0.013 & 0.012 & 0.011 & 0.010 & 0.015 & 0.013 & 0 & 0.025 & 0.018 & 0.117 & -0.052 \\
\hline H215M & 0.010 & 0.015 & 0.011 & 0.007 & 0.017 & 0.009 & 0.013 & 0 & 0.011 & 0.093 & -0.148 \\
\hline H160M & 0.015 & 0.017 & 0.011 & 0.012 & 0.020 & 0.015 & 0.018 & 0.014 & 0 & 0.122 & -0.100 \\
\hline$\phi^{-}$ & 0.086 & 0.144 & 0.078 & 0.062 & 0.149 & 0.056 & 0.169 & 0.241 & 0.222 & & \\
\hline
\end{tabular}

\subsection{Result Analysis}

As explored in the previous sections, the proposed model enables three models of results in search to obtain a sensitivity analysis of the problem. The three models are based on a partial, complete, and intervals outranking. In the software, a graphical representation was enabled, generating three charts after entering data. Figure 5 exposes the graphical analysis interface. Remembering that the positive and negative flow provide the partial ranking, the complete ranking handles the net flows, and the ranking by intervals is built by the lower and upper limit, with all values detailed in Table 14.

First, the performances concerning the partial outranking were analyzed. In the Partial Pre-ordering graphic exposed in Figure 5, the right line represents the positive flows and the left line the negative flows, whereas the higher the positive and the lower the negative, the better is the alternative, represented by the crossing of lines. It is possible to note that the alternative with the best performance is the helicopter APACHE, presenting the highest positive flow and the lowest negative flow, exposing a total preference over the set. The following most preferable alternatives are Katran, VIPER, and T129 ATAK, respectively. Concerning the alternatives, Tiger and Sikorsky S-70, both presented an incompatible relation regarding the alternative MI-35M. In this analysis, the alternative H160M becomes preferable only over $\mathrm{H} 215 \mathrm{M}$, which was worse than all alternatives. 


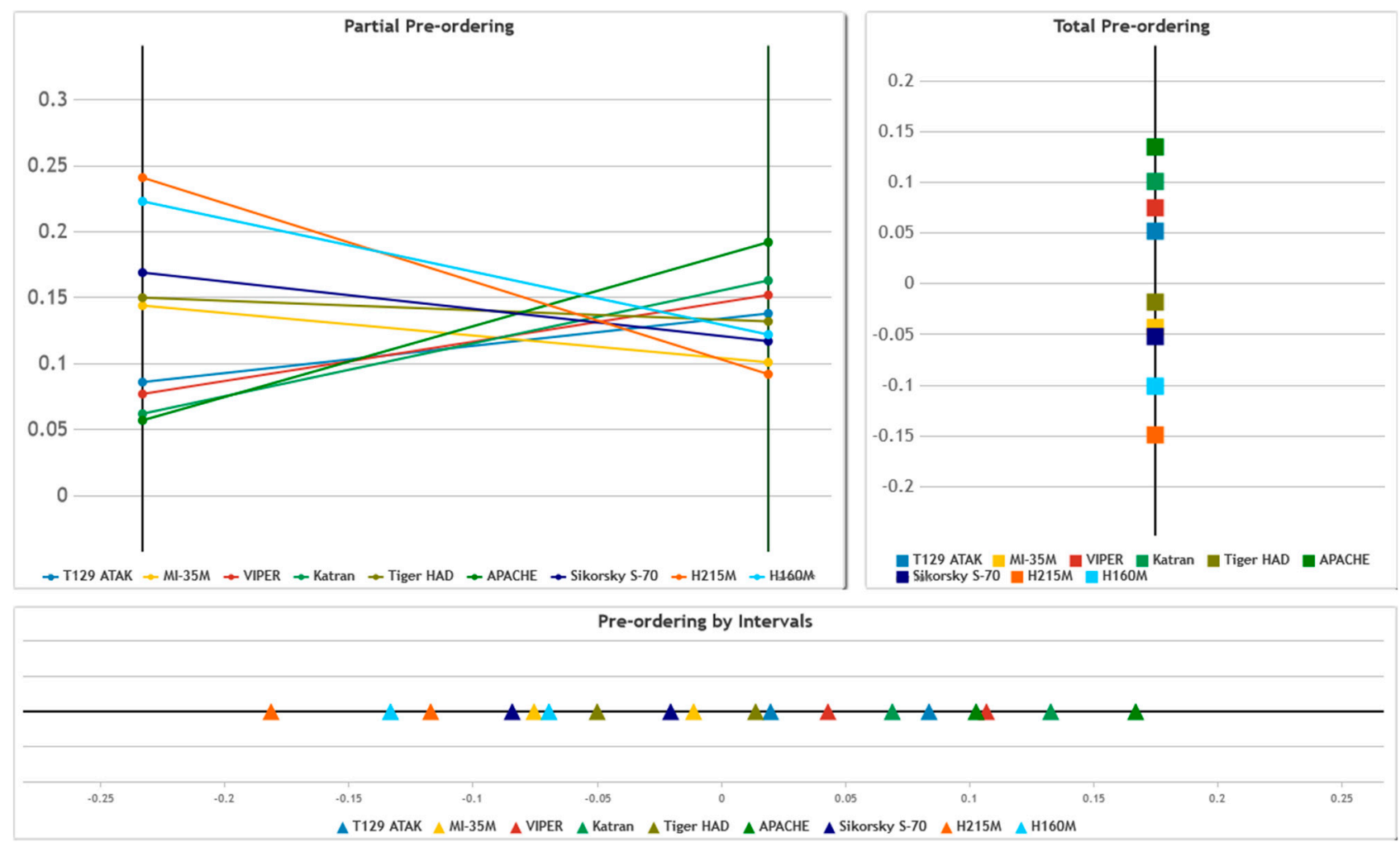

Figure 5. Charts generated by the web platform based in the three models of preference analysis.

Table 14. Lower and upper limits for construction of preference analysis by intervals.

\begin{tabular}{cccc}
\hline & Net Flow $(\boldsymbol{\phi})$ & Lower Limit $(\boldsymbol{x})$ & Upper Limit $(\mathbf{y})$ \\
\hline T129 ATAK & 0.051 & 0.019 & 0.083 \\
MI-35M & -0.044 & -0.076 & -0.012 \\
VIPER & 0.074 & 0.042 & 0.106 \\
Katran & 0.101 & 0.069 & 0.133 \\
Tiger HAD & -0.018 & -0.05 & 0.014 \\
APACHE & 0.136 & 0.104 & 0.168 \\
Sikorsky S-70 & -0.052 & -0.084 & -0.020 \\
H215M & -0.148 & -0.180 & -0.116 \\
H160M & -0.100 & -0.132 & -0.068 \\
\hline \multicolumn{4}{c}{ Standard error $=0.032$} \\
\hline
\end{tabular}

The second analysis is based on the Total Pre-ordering as exposed in Figure 5, just ranking the alternatives over the line of net flows. In this evaluation, the alternative APACHE continued to present the best ranking, preceded by Katran, VIPER, T129 ATAK, Tiger, MI-35M, Sikorsky S-70, H160M, and H215M, respectively, in this order. Even presenting a simple format of analysis, the model enables to identify preference relation in cases that exposed an incompatible relation in the previous analysis, where it was possible to note regarding the alternatives Tiger and Sikorsky S-70 concerning the alternative MI-35M.

As presented in Table 14 and Figure 5, the intervals of alternatives based on the standard error of 0.032 were constructed. Based on the graph, a preference relation is indicated, when there is no intersection between intervals, otherwise, a relationship of indifference is indicated. This analysis model makes it possible to understand if an alternative is relatively superior concerning another or if the difference between the preferences is so small that both can become equivalent. It is noticeable that in this type of evaluation, the alternative APACHE becomes indifferent regarding alternatives Katran and, by a minimum difference, also becomes indifferent to VIPER. It is possible to observe that the alternatives Tiger, 
MI-35M, and Sikorsky S-70 presented a relation of indifference between each other. In this analysis, the alternative H215M becomes indifferent regarding H160M, although sustained outranked concerning the other from the set.

Based on the transitive relation of preference and non-transitive relation of indifference, it is possible to allocate each alternative into a group, representing its relation of preference over the other. As exposed in Figure 6, allocating some alternatives into groups of indifference, it is clearer to understand the relation of transitive preference and intransitive indifference between the alternatives.

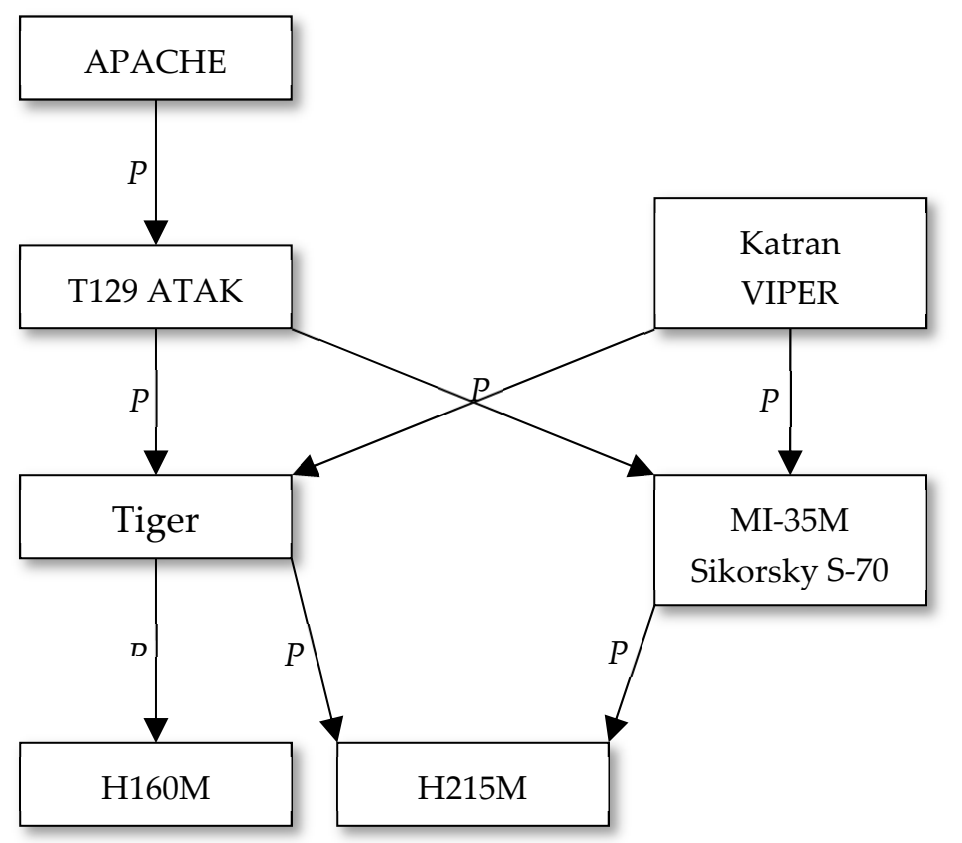

Figure 6. Graph or preference between the alternatives based in the outranking.

In the given analysis, the intra-criterion evaluation was carried out regarding the alternatives $\mathrm{H} 160 \mathrm{M}$ and $\mathrm{H} 215 \mathrm{M}$, trying to identify some presence or preference relations regarding the veto thresholds, by the moment that both of them presented a low performance in the global evaluation. As presented in Table 15, the unique criterion with a relative dominance of these alternatives is related to Troop capacity, although, presenting low importance. Regarding the other criteria, these alternatives did not present any relative relation of preference. In this case, the intra-criterion model served to prove the weak performance of these alternatives, even when considering a particular criterion.

Table 15. Intra-criterion analysis regarding the criterion Troop capacity.

\begin{tabular}{cccccccccc}
\hline & $\begin{array}{c}\text { T129 } \\
\text { ATAK }\end{array}$ & $\begin{array}{c}\text { MI- } \\
\text { 35M }\end{array}$ & VIPER & Katran & $\begin{array}{c}\text { Tiger } \\
\text { HAD }\end{array}$ & $\begin{array}{c}\text { APACHE } \\
\begin{array}{c}\text { Sikorsky } \\
\text { S-70 }\end{array}\end{array}$ H215M & H160M \\
\hline T129 ATAK & 0 & -8 & 0 & 0 & 0 & 0 & -13 & -20 & -12 \\
MI-35M & 8 & 0 & 8 & 8 & 8 & 8 & -5 & -12 & -4 \\
VIPER & 0 & -8 & 0 & 0 & 0 & 0 & -13 & -20 & -12 \\
Katran & 0 & -8 & 0 & 0 & 0 & 0 & -13 & -20 & -12 \\
Tiger HAD & 0 & -8 & 0 & 0 & 0 & 0 & -13 & -20 & -12 \\
APACHE & 0 & -8 & 0 & 0 & 0 & 0 & -13 & -20 & -12 \\
Sikorsky & 13 & 5 & 13 & 13 & 13 & 13 & 0 & -7 & 1 \\
S-70 & 20 & 12 & 20 & 20 & 20 & 20 & 7 & 0 & 8 \\
H215M & 12 & 4 & 12 & 12 & 12 & 12 & -1 & -8 & 0 \\
H160M & 12 & & & & & & &
\end{tabular}




\subsection{Rank Reversal Analysis}

Even with the methodology providing the identification of the most favorable alternatives, a rank reversal procedure was carried out. The procedure is characterized by the change in the alternative ranking as a consequence of the addition or deletion of alternatives [85]. Furthermore, the process in search to identify the presence of dependencies between the alternatives is realized, by the moment that the removal of one alternative can generate a change of ranking.

In this context, the removal of alternatives $\mathrm{H} 215 \mathrm{M}$ and $\mathrm{H} 160$ will occur, as long as both of them presented low performance and interest to the objectives. Considering that the APACHE alternative is a favorable solution, it was also removed to identify a second or third favorable alternative to implementation in the operations of BN. After the procedure, a new Global Index of preference is obtained, as presented in Table 16, as well as this graphical performance, based on total outranking, is exposed in Figure 7.

Table 16. Global Index of preference along with the outranking flows after rank reversal procedure.

\begin{tabular}{|c|c|c|c|c|c|c|c|c|}
\hline & $\begin{array}{c}\text { T129 } \\
\text { ATAK }\end{array}$ & MI-35M & VIPER & Katran & $\begin{array}{l}\text { Tiger } \\
\text { HAD }\end{array}$ & $\begin{array}{l}\text { Sikorsky } \\
\text { S-70 }\end{array}$ & $\phi^{+}$ & $\phi$ \\
\hline T129 ATAK & 0 & 0.027 & 0.008 & 0.007 & 0.017 & 0.031 & 0.090 & 0.017 \\
\hline MI-35M & 0.013 & 0 & 0.003 & 0.003 & 0.023 & 0.017 & 0.059 & -0.065 \\
\hline VIPER & 0.013 & 0.024 & 0 & 0.006 & 0.027 & 0.037 & 0.107 & 0.054 \\
\hline Katran & 0.022 & 0.032 & 0.014 & 0 & 0.027 & 0.040 & 0.136 & 0.101 \\
\hline Tiger HAD & 0.012 & 0.029 & 0.017 & 0.009 & 0 & 0.033 & 0.100 & -0.010 \\
\hline $\begin{array}{c}\text { Sikorsky } \\
\text { S-70 }\end{array}$ & 0.013 & 0.012 & 0.011 & 0.010 & 0.015 & 0 & 0.061 & -0.097 \\
\hline$\phi^{-}$ & 0.073 & 0.124 & 0.053 & 0.035 & 0.110 & 0.158 & & \\
\hline
\end{tabular}

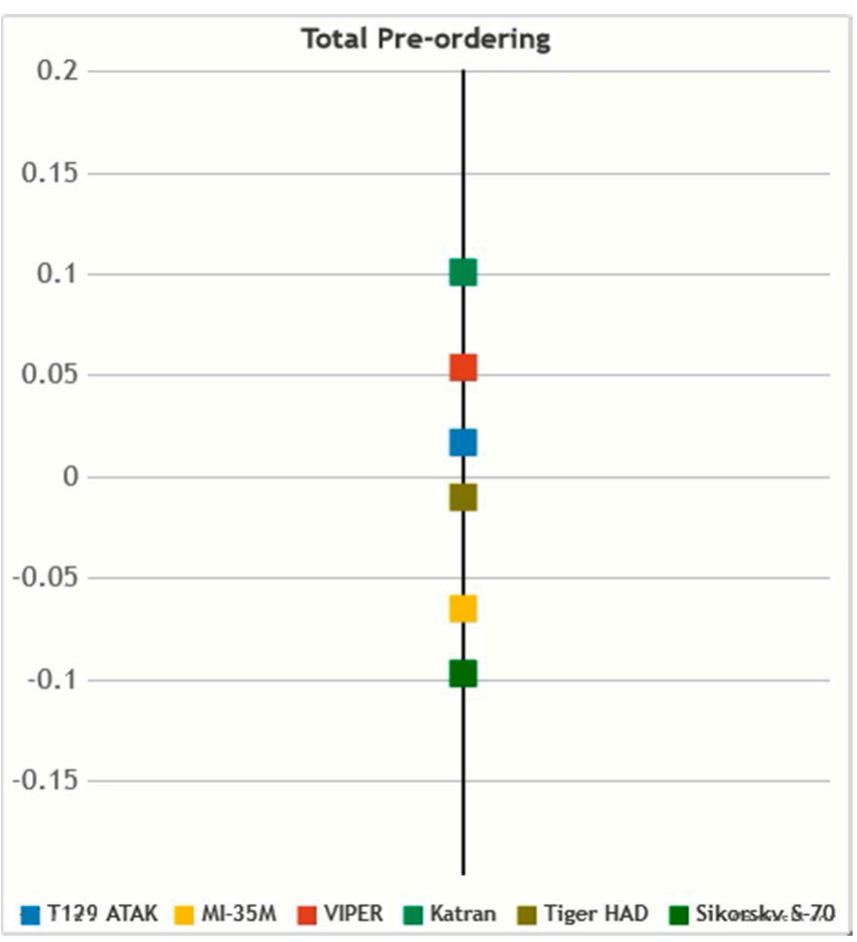

Figure 7. Total outranking after the rank reversal procedure.

Based on the new net outranking flows and considering a total preference analysis, it is observed that the outranking relation between alternatives sustained their positions. Regarding this new evaluation, in Figure 7, it is noticeable an approximation between the alternatives T129 ATAK to Tiger HAD and a distance increase relative to alternatives MI-35M and Sikorsky S-70. 
Even though the process did not present any change in the final outranking, the process presents great value for the analysis by the moment that this consideration proves the relation of independence into the set of alternatives; in other words, the presence of an alternative does not present any influence or dependence concerning other variables in the context. The final ranking obtained is Katran, VIPER, T129 ATAK, Tiger, MI-35M, and Sikorsky S-70, in this order, respectively.

\subsection{Comparison Analysis}

Exploring the evolution points of the PROMETHEE-SAPEVO-M1 approach concerning its precedents two types of comparative analyzes were performed. One analysis realizes the implementation of the case study in the PROMETHEE method in its classic form, exposing the main differences obtained between the results in both models. Another analysis explores the integration of qualitative and quantitative criteria, where implementation is carried out for each nature, exposing the benefits of hybrid evaluation.

\subsubsection{Comparison of the Classic PROMETHEE Method}

For the given process, the same weights values obtained in the application of the case study were used, although it is worth mentioning that the traditional model does not provide the obtaining of weights to the criteria set, in this case, the values are attributed directly, understanding this factor as a point of evolution in the proposed approach.

For the implementation of the case study, the Visual PROMETHEE software was used [86]. In this case, the evaluation of the alternatives in the qualitative criteria used the attributions provided by the given model, based on a scale of five points (very bad, bad, average, good, and very good). After the evaluation, Table 17 presents the final rankings obtained in PROMETHEE-SAPEVO-M1 and PROMETHEE methods.

Table 17. Complete ranking in PROMETHEE-SAPEVO-M1 and PROMETHEE method.

\begin{tabular}{|c|c|c|c|}
\hline \multicolumn{2}{|c|}{$\begin{array}{l}\text { PROMETHEE-SAPEVO-M1 } \\
\text { Complete Ranking }\end{array}$} & \multicolumn{2}{|c|}{$\begin{array}{c}\text { PROMETHEE } \\
\text { Complete Ranking }\end{array}$} \\
\hline Ranking & Net Flow $(\phi)$ & Ranking & Net Flow $(\phi)$ \\
\hline APACHE & 0.136 & Katran & 0.324 \\
\hline Katran & 0.101 & APACHE & 0.272 \\
\hline VIPER & 0.074 & VIPER & 0.207 \\
\hline T129 ATAK & 0.051 & T129 ATAK & 0.022 \\
\hline Tiger HAD & -0.018 & Tiger HAD & -0.036 \\
\hline MI-35M & -0.044 & MI-35M & -0.095 \\
\hline Sikorsky S-70 & -0.052 & H160M & -0.162 \\
\hline H160M & -0.100 & $\mathrm{H} 215 \mathrm{M}$ & -0.248 \\
\hline $\mathrm{H} 215 \mathrm{M}$ & -0.148 & Sikorsky S-70 & -0.285 \\
\hline
\end{tabular}

Through the results exposed in Table 16, regarding the PROMETHEE method, there is a variation between the obtained scores and sequence of alternatives in the final ranking. In this context, the alternative Katran placed the first ranking position, being preceded by APACHE. The helicopters Sikorsky S-70, H160M, and H215M also showed a change in their scores and positioning in the ranking. A great point of importance is that even with some alternatives maintaining their positions in the ranking, there was a relative distance between the net flows, as observed between the alternatives VIPER and T129 ATAK. The graph exposed in Figure 8 enables a clearer understanding of this distance.

Based on this comparison analysis, the introduction of an evaluation in qualitative criteria in a more detailed way, as provided by the pairwise evaluation in the PROMETHEESAPEVO-M1 approach, proved to enable a better accuracy of the subjective opinion of the decision-maker, making the applied model perform a better representation of reality. 


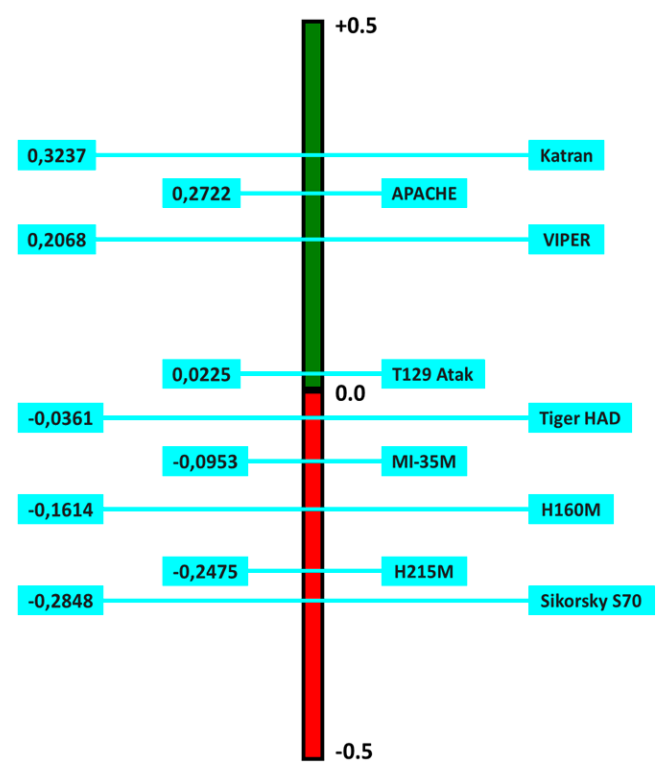

Figure 8. Complete ranking in the PROMETHEE method, adapted from [86].

\subsubsection{Evaluation Using Only One Type of Nature}

In a search to understand the importance of the integration of both qualitative and quantitative nature in the evaluation, two more evaluations were carried out, one of them performing the alternatives under only quantitative criteria and another considering only the ordinal inputs regarding qualitative criteria. Table 18 presents the criteria weights obtained in each model of evaluation, respecting the amount of weights for each performance, where $\sum w_{j}=1$.

Table 18. Criteria weights in scenarios considering only quantitative or qualitative nature.

\begin{tabular}{cccc}
\hline \multicolumn{2}{c}{$\begin{array}{c}\text { Evaluation Based Only in } \\
\text { Qualitative Criteria }\end{array}$} & \multicolumn{2}{c}{$\begin{array}{c}\text { Evaluation Based Only in } \\
\text { Quantitative Criteria }\end{array}$} \\
\hline Criteria & Weights & Criteria & Weights \\
\hline Technological level & 0.144 & Maximum speed & 0.137 \\
Main cannon system & 0.211 & Cruising speed & 0185 \\
Missiles system & 0.211 & Range & 0.137 \\
Armament subsystems & 0.211 & Autonomy & 0.137 \\
Armor level & 0.211 & Service ceiling & 0.048 \\
Employment flexibility & 0.012 & Maximum payload & 0.220 \\
& & Troop capacity & 0.088 \\
& & Length & 0.048 \\
\hline
\end{tabular}

When the aggregation of preferences is realized, a new total outranking for each evaluation is obtained. Table 19 exposes the new ranking and the obtained net flows regarding alternatives.

As observed in Table 19, considering the performance only under qualitative criteria, there is a change of the ranking between the alternatives Tiger HAD, VIPER, and T129 compared to the original evaluation is noticeable. Meanwhile, when the evaluation is realized only regarding quantitative criteria, there is a change of positions regarding all alternatives from the set, where alternatives with low performance in the original evaluation, presented as the most favorable when considered only quantitative nature.

This procedure aims to explore the importance of considering not only quantitative data but also qualitative data, as performed by the proposed model. In this way, when there is the integration of both natures into a model, and it is taken into account the decision-maker subjectivity, a more realistic process is performed, providing an assertive final decision. 
Table 19. Complete ranking in scenarios considering only quantitative or qualitative nature.

\begin{tabular}{cccc}
\hline $\begin{array}{c}\text { Complete Outranking } \\
\text { Considering Only } \\
\text { Qualitative Criteria }\end{array}$ & $\boldsymbol{\phi}$ & $\begin{array}{c}\text { Complete Outranking } \\
\text { Considering Only } \\
\text { Quantitative Criteria }\end{array}$ & $\boldsymbol{\phi}$ \\
\hline APACHE & 0.618 & H215M & 0.199 \\
Katran & 0.355 & H160M & 0.141 \\
Tiger HAD & 0.335 & Sikorsky S-70 & 0.116 \\
VIPER & 0.269 & Katran & 0.057 \\
T129 ATAK & 0.249 & VIPER & 0.043 \\
MI-35M & -0.002 & T129 ATAK & -0.026 \\
Sikorsky S-70 & -0.328 & APACHE & -0.028 \\
H160M & -0.642 & MI-35M & -0.172 \\
H215M & -0.854 & Tiger & -0.2330 \\
\hline
\end{tabular}

\section{Discussion}

A method based on MCDA concepts requires a set of techniques to enable an evaluation of the real-world problem, where often it is constituted by a lack of data, risk, uncertainty, and divergent opinion [87]. Regarding this context, the proposed modeling by its algorithm aimed to make it possible to take into account the decision-maker subjectivity, always presented regarding the preference of an alternative or the importance of a criterion.

The main point of the approach concerns its model of ordinal evaluation, enabling to perform alternatives in a qualitative criterion, and weights obtained. As aborded in [37], there are some studies where the qualitative data in a method is evaluated, and then, the cardinal value is aggregated into another method. Although, the PROMETHEE-SAPEVOM1 modeling proposed to perform all the processes in unique modeling, enabling an evaluation closer to reality concerning the problem, as addressed in Section 4. Clarifying, the ordinal model approached makes it possible to obtain numerical quantities by specifying preferences between two variables (alternatives or criteria), thus, it is not necessary to indicate a global ordering, but only a relative order or preference between two variables.

In a decision-making analysis, the set of criteria weights is one of the main parts of the process by the moment that the weight presents directly influences the final decision suggestion. Regarding the proposed model, the pairwise evaluation is efficient, considering that sometimes it is not easy to set the global importance of a variable [88], provided by a simple set of preferences between two criteria and determining the global importance as a weight.

The integration of three models of preference analysis brings a robust format for the proposed model. It is common to find studies performing the partial and complete outranking together, the PROMETHEE I and PROMETHEE II methods, respectively, although it was not identified in the literature the integration of analysis using the outranking by intervals (PROMETHEE III). The model proposed enabled the sensitivity analysis, evaluating the performance of the alternatives in different models of manipulation and comparing them in the search to obtain a final decision based on the inter-criterion and intra-criterion analysis.

The development of a proposal along with a computational tool brings gains for implementation and expansion regarding applications by other researchers, presenting a simple interface of data input and generating a robust analysis of results. It is a fact that the software implementation is the last step of a decision-making process [89], but essential for an efficient evaluation along with its graphical representation of results. Based on [13], technological support can improve the comprehensibility of the decision recommendation through an advanced exploration of the results and graphic resources.

Regarding the case study approached, it was possible to understand the problem and structure concerning the achievement of previously identified objectives. The evaluation based on the PROMETHEE-SAPEVO-M1 modeling enabled the outranking of alternatives, not only considering the best option but taking into account a second or third favorable alternative for implementation in BN operations, also allowing considering the employment 
of multiple aircrafts. A relevant point to highlight is that due to the process that worked, not only the most favorable aircrafts were identified in the context, but it also allowed us to identify non-favorable models. In this case, as important as knowing what is favorable to do is the identification of an alternative that will not be consistent with the reality of the problem constraints.

\section{Conclusions}

The paper proposed a MCDA modeling named PROMETHEE-SAPEVO-M1. The modeling is a novel approach based on the PROMETHEE methods, integrating the concepts presented in two multi-criteria methods, enabling performing quantitative and qualitative data simultaneously.

The approach covered a structure composed of five steps, where was integrated an ordinal evaluation into the previous cardinal format of the PROMETHEE method, enabling the evaluation of alternatives regarding criteria based on a qualitative view and performing a pairwise evaluation between the criteria for weight obtaining. Concerning the analysis of the results, four different approaches were carried out, three related to different models of preference analysis based on the outranking flows, and one regarding an intra-criterion analysis by veto threshold, allowing generating more information as a way of supporting the final decision. Even though the veto did not influence the obtaining of the outranking flows, the value indicates degrees of differences that may induce a possible change in the final decision.

The case study addressed a real-world problem regarding the evaluation of attack helicopters to support the BN operations in search to expose the applicability of the proposed modeling. All the steps of the procedure were detailed, focusing on the performance of ordinal evaluation. In addition to the sensitivity analysis, also, a rank reversal process and comparative analysis were performed in different scenarios, comparing the obtained results concerning the previous evaluation and exposing the robustness of the modeling.

In search of an expansion of the proposal, a web platform was developed, supporting the implementation of the algorithm and providing its application in different areas of science, by specialists and non-specialists, at operational, tactical, and strategic levels, enabling satisfactory results along with robust analysis, through numerical and graphical presentations.

It concludes, therefore, that the modeling can be used to solve the most diverse real problems of daily life, thus, being a useful model aimed at the contribution of high-level decision making. Regarding future works, the application of the PROMETHEE-SAPEVOM1 modeling as an aggregation model in studies based on prospective scenarios and its implementation in other real-world problems is suggested, making it possible to identify some improvements in the axiomatic modeling and its computational platform.

Author Contributions: Conceptualization, M.Â.L.M., I.P.d.A.C., M.T.P., M.d.S. and C.F.S.G.; methodology, M.Â.L.M., M.d.S. and C.F.S.G.; software, M.Â.L.M., M.d.S. and C.F.S.G.; validation, M.Â.L.M., I.P.d.A.C., M.T.P., M.d.S. and C.F.S.G.; writing-original draft preparation, M.Â.L.M., I.P.d.A.C., M.T.P., M.d.S., C.F.S.G. and F.M.M.; supervision, M.T.P., M.d.S. and C.F.S.G.; funding acquisition, M.T.P. All authors have read and agreed to the published version of the manuscript.

Funding: This research was funded by Centre for Research \& Development in Mechanical Engineering (CIDEM), School of Engineering of Porto (ISEP), Polytechnic of Porto, Rua Dr. António Bernardino de Almeida, 431 4249-015 Porto, Portugal.

Institutional Review Board Statement: Not Applicable.

Informed Consent Statement: Not Applicable.

Data Availability Statement: Not Applicable.

Conflicts of Interest: The authors declare no conflict of interest. 


\section{References}

1. Senado Federal. Constituição da República Federativa do Brasil; Senado Federal: Brasília, Brazil, 1988.

2. Marinha do Brasil. Doutrina Básica da Marinha 2014; Marinha do Brasil: Brasília, Brazil, 2014; p. 103.

3. Cepik, M.; Licks Bertol, F. Defense policy in Brazil: Bridging the gap between ends and means? Def. Stud. 2016, 16, 229-247. [CrossRef]

4. Marinha do Brasil. Naval Policy. Available online: https://www.marinha.mil.br/politicanaval (accessed on 14 January 2021).

5. Paiva, L.E.R. Direcionamento Estratégico do Exército Para a Defesa e Projeção de Poder do Brasil na Pan-Amazônia. In Amazônia e Atlântico Sul, Desafios e Perspectivas Para a Defesa no Brasil; Gheller, G.F., de Gonzales, S.L.M., de Melo, L.P., Eds.; IPEA: Brasília, Brazil, 2015; ISBN 9788578112509.

6. Hashemkhani Zolfani, S.; Zavadskas, E.K.; Turskis, Z. Design of products with both international and local perspectives based on Yin-Yang balance theory and SWARA method. Ekon. Istraz. 2013, 26, 153-166. [CrossRef]

7. Teixeira Júnior, A.W.M. Para Pensar a Transformação do Exército. Available online: http://eblog.eb.mil.br/index.php/menueasyblog/para-pensar-a-transformacao-do-exercito.html (accessed on 14 January 2021).

8. Marinha do Brasil Estado Maior da Armada. EMA-305: Doutrina Militar Naval, 1st ed.; Marinha do Brasil: Brasilia, Brazil, 2017.

9. Brasil. Emprego da Aviação do Exército; Exército Brasileiro: Brasilia, Brazil, 2000.

10. Brasil. Política Nacional de Defesa. Estratégia Nacional de Defesa; Ministério da Defesa: Brasilia, Brazil, 2020 ; p. 41.

11. Brasil. Manual de Campanha: Vetores Aéreos da Força Terrestre; Exército Brasileiro: Brasilia, Brazil, 2020.

12. Belton, V.; Stewart, T.J. Multiple Criteria Decision Analysis; Springer US: Boston, MA, USA, 2002; ISBN 978-1-4613-5582-3.

13. Ishizaka, A.; Nemery, P. Multi-Criteria Decision Analysis: Methods and Software; John Wiley \& Sons: Hoboken, NJ, USA, 2013; ISBN 9781118644898 .

14. Zopounidis, C.; Doumpos, M. Multiple Criteria Decision Making: Applications in Management and Engineering; Springer: Cham, Switzerland, 2016. [CrossRef]

15. De Souza, L.P.; Gomes, C.F.S.; De Barros, A.P. Implementation of New Hybrid AHP-TOPSIS-2N Method in Sorting and Prioritizing of an it CAPEX Project Portfolio. Int. J. Inf. Technol. Decis. Mak. 2018, 17, 977-1005. [CrossRef]

16. Tenório, F.M.; dos Santos, M.; Gomes, C.F.S.; de Carvalho Araujo, J. Navy Warship Selection and Multicriteria Analysis: The THOR Method Supporting Decision Making. In Springer Proceedings in Mathematics E Statistics; Springer: Cham, Switzerland, 2020; Volume 337. [CrossRef]

17. Üsküdar, A.; Türkan, Y.S.; Özdemir, Y.S.; Öz, A.H. Fuzzy AHP—Center of Gravity Method Helicopter Selection and Application. In Proceedings of the 2019 8th International Conference on Industrial Technology and Management (ICITM), Cambridge, UK, 2-4 March 2019; pp. 170-174.

18. Ahmadi, S.H.S.; Suharyo, O.S.; Susilo, A.K. Selection anti submarine sensor of helicopter using ELECTRE III method. Int. J. Appl. Eng. Res. 2017, 12, 1974-1981.

19. Hamurcu, M.; Eren, T. Selection of Unmanned Aerial Vehicles by Using Multicriteria Decision-Making for Defence. J. Math. 2020. [CrossRef]

20. de Araújo Costa, I.P.; do Nascimento Maêda, S.M.; de Souza de Barros Teixeira, L.F.H.; Simões Gomes, C.F.; dos Santos, M. Choosing a hospital assistance ship to fight the covid-19 pandemic. Revista De Saúde Pública 2020, 54, 79. [CrossRef] [PubMed]

21. Malloy, T.F.; Zaunbrecher, V.M.; Batteate, C.M.; Blake, A.; Carroll, W.F.; Corbett, C.J.; Hansen, S.F.; Lempert, R.J.; Linkov, I.; McFadden, R.; et al. Advancing alternative analysis: Integration of decision science. Environ. Health Perspect. 2017, $125,066001$. [CrossRef]

22. Doumpos, M.; Zopounidis, C. A multicriteria decision support system for bank rating. Decis. Support Syst. 2010, 50, 55-63. [CrossRef]

23. Durbach, I.N.; Stewart, T.J. Modeling uncertainty in multi-criteria decision analysis. Eur. J. Oper. Res. 2012, 223, 1-14. [CrossRef]

24. Dong, Y.; Liu, Y.; Liang, H.; Chiclana, F.; Herrera-Viedma, E. Strategic weight manipulation in multiple attribute decision making. Omega 2018, 75, 1339-1351. [CrossRef]

25. Wibowo, S.; Deng, H.; Xu, W. Evaluation of cloud services: A fuzzy multi-criteria group decision making method. Algorithms 2016, 9, 84. [CrossRef]

26. Brans, J.-P.; Smet, Y. De PROMETHEE methods. In Multiple Criteria Decision Analysis: State of the Art Surveys; Springer: New York, NY, USA, 2016; Volume 233, pp. 927-976. ISBN 978-1-4939-3093-7.

27. Munier, N.; Hontoria, E.; Jiménez-Saez, F. Strategic Approach in Multi-Criteria Decision Making-A Practical Guide for Complex Scenarios, 1st ed.; Springer: Cham, Switzerland, 2019; ISBN 9783030027254.

28. Maghrabie, H.F.; Beauregard, Y.; Schiffauerova, A. Grey-based Multi-Criteria Decision Analysis approach: Addressing uncertainty at complex decision problems. Technol. Forecast. Soc. Chang. 2019, 146, 366-379. [CrossRef]

29. Santos, M.; Quintal, R.S.; Da Paixão, A.C.; Gomes, C.F.S. Simulation of operation of an integrated information for emergency pre-hospital care in rio de janeiro municipality. Procedia Comput. Sci. 2015, 55, 931-938. [CrossRef]

30. Espie, P.; Ault, G.W.; Mcdonald, J.R.; Ixw, G. Multiple Criteria Decision Making-Applications in Management and Engineering; Springer: New York, NY, USA, 2017; ISBN 078035902X.

31. Greco, S.; Figueira, J.; Ehrgott, M. Multiple Criteria Decision Analysis; Greco, S., Ehrgott, M., Figueira, J.R., Eds.; International Series in Operations Research \& Management Science; Springer: New York, NY, USA, 2016; Volume 233, ISBN 978-1-4939-3093-7. 
32. Akram, M.; Al-Kenani, A.N. Multiple-attribute decision making ELECTRE II method under bipolar fuzzy model. Algorithms 2019, 12, 226. [CrossRef]

33. Gomes, C.F.S.; Nunes, K.R.A.; Helena Xavier, L.; Cardoso, R.; Valle, R. Multicriteria decision making applied to waste recycling in Brazil. Omega 2008, 36, 395-404. [CrossRef]

34. Kilic, H.S.; Demirci, A.E.; Delen, D. An integrated decision analysis methodology based on IF-DEMATEL and IF-ELECTRE for personnel selection. Decis. Support Syst. 2020, 137, 113360. [CrossRef]

35. Chen, Y.; Kilgour, D.M.; Hipel, K.W. Screening in multiple criteria decision analysis. Decis. Support Syst. 2008, 45, 278-290. [CrossRef]

36. Roy, B. Multicriteria Methodology for Decision Aiding; Nonconvex Optimization and Its Applications; Springer: Boston, MA, USA, 1996; Volume 12, ISBN 978-1-4419-4761-1.

37. Velasquez, M.; Hester, P. An analysis of multi-criteria decision making methods. Int. J. Oper. Res. 2013, $10,56-66$.

38. Jayant, A.; Agarwal, A. A novel hybrid MCDM approach based on DEMATEL, AHP and TOPSIS to evaluate green suppliers. J. Phys. Conf. Ser. 2019, 1240, 12010.

39. Kazemi-Beydokhti, M.; Abbaspour, R.A.; Kheradmandi, M.; Bozorgi-Amiri, A. Determination of the physical domain for air quality monitoring stations using the ANP-OWA method in GIS. Environ. Monit. Assess. 2019, 191, 1-17. [CrossRef] [PubMed]

40. You, P.; Guo, S.; Zhao, H.; Zhao, H. Operation performance evaluation of power grid enterprise using a hybrid BWM-TOPSIS method. Sustainability 2017, 9, 2329. [CrossRef]

41. Wan, S.; Xu, G.; Dong, J. Supplier selection using ANP and ELECTRE II in interval 2-tuple linguistic environment. Inf. Sci. 2017, 385, 19-38. [CrossRef]

42. Brans, J.P.; Vincke, P. A Preference Ranking Organisation Method: (The PROMETHEE Method for Multiple Criteria DecisionMaking). Manag. Sci. 1985, 31, 647-656. [CrossRef]

43. Brans, J.P.; De Smet, Y. PROMETHEE methods. Int. Ser. Oper. Res. Manag. Sci. 2016, 233, 187-219. [CrossRef]

44. Brans, J.P.; Vincke, P.; Mareschal, B. How to select and how to rank projects: The Promethee method. Eur. J. Oper. Res. 1986, 24, 228-238. [CrossRef]

45. Behzadian, M.; Kazemzadeh, R.B.; Albadvi, A.; Aghdasi, M. PROMETHEE: A comprehensive literature review on methodologies and applications. Eur. J. Oper. Res. 2010, 200, 198-215. [CrossRef]

46. Doan, N.A.V.; De Smet, Y. An alternative weight sensitivity analysis for PROMETHEE II rankings. Omega 2018, 80, 166-174. [CrossRef]

47. Brans, J.P.; Mareschal, B. The PROMCALC \& GAIA decision support system for multicriteria decision aid. Decis. Support Syst. 1994, 12, 297-310. [CrossRef]

48. Tzeng, G.-H.; Huang, J.-J. PROMETHEE Method. In Multiple Attribute Decision Making; CRC Press: Boca Raton, FL, USA, 2011; pp. 95-102.

49. Brans, J.P.; Mareschal, B. Promethee V: Mcdm Problems With Segmentation Constraints. Infor: Inf. Syst. Oper. Res. 1992, 30, 85-96. [CrossRef]

50. Brans, J.-P.; Mareschal, B. The PROMETHEE VI procedure: How to differentiate hard from soft multicriteria problems. J. Decis. Syst. 1995, 4, 213-223. [CrossRef]

51. Brans, J.-P.; Mareschal, B. Promethee Methods-Multiple Criteria Decision Analysis: State of the Art Surveys; Figueira, J., Greco, S., Ehrogott, M., Eds.; Springer: New York, NY, USA, 2005; pp. 163-186. ISBN 978-0-387-23081-8.

52. Yilmaz, B.; Dağdeviren, M. A combined approach for equipment selection: F-PROMETHEE method and zero-one goal programming. Expert Syst. Appl. 2011, 38, 11641-11650. [CrossRef]

53. Chen, T.Y. IVIF-PROMETHEE outranking methods for multiple criteria decision analysis based on interval-valued intuitionistic fuzzy sets. Fuzzy Optim. Decis. Mak. 2015, 14, 173-198. [CrossRef]

54. Ziemba, P. NEAT F-PROMETHEE-A new fuzzy multiple criteria decision making method based on the adjustment of mapping trapezoidal fuzzy numbers. Expert Syst. Appl. 2018, 110, 363-380. [CrossRef]

55. Chen, L.; Xu, Z. A new prioritized multi-criteria outranking method: The prioritized PROMETHEE. J. Intell. Fuzzy Syst. 2015, 29, 2099-2110. [CrossRef]

56. Zhan, J.; Jiang, H.; Yao, Y. Covering-based variable precision fuzzy rough sets with PROMETHEE-EDAS methods. Inf. Sci. 2020, 538, 314-336. [CrossRef]

57. Alinezhad, A.; Khalili, J. EXPROM I \& II Method. In International Series in Operations Research and Management Science; Springer: New York, NY, USA, 2019; Volume 277, pp. 181-191.

58. Turcksin, L.; Bernardini, A.; Macharis, C. A combined AHP-PROMETHEE approach for selecting the most appropriate policy scenario to stimulate a clean vehicle fleet. Procedia Soc. Behav. Sci. 2011, 20, 954-965. [CrossRef]

59. Halouani, N.; Chabchoub, H.; Martel, J.M. PROMETHEE-MD-2T method for project selection. Eur. J. Oper. Res. 2009, 195, 841-849. [CrossRef]

60. Corrente, S.; Figueira, J.R.; Greco, S. The SMAA-PROMETHEE method. Eur. J. Oper. Res. 2014, 239, 514-522. [CrossRef]

61. Greco, S.; Ishizaka, A.; Tasiou, M.; Torrisi, G. The ordinal input for cardinal output approach of non-compensatory composite indicators: The PROMETHEE scoring method. Eur. J. Oper. Res. 2021, 288, 225-246. [CrossRef]

62. Morais, D.C.; De Almeida, A.T.; Alencar, L.H.; Clemente, T.R.N.; Cavalcanti, C.Z.B. PROMETHEE-ROC model for assessing the readiness of technology for generating energy. Math. Probl. Eng. 2015, 2015. [CrossRef] 
63. Sarrazin, R.; De Smet, Y.; Rosenfeld, J. An extension of PROMETHEE to interval clustering. Omega 2018, 80, 12-21. [CrossRef]

64. De Smet, Y. P2CLUST: An extension of PROMETHEE II for multicriteria ordered clustering. In Proceedings of the 2013 IEEE International Conference on Industrial Engineering and Engineering Management, Bangkok, Thailand, 10-13 December 2013; pp. 848-851. [CrossRef]

65. Araz, C.; Ozkarahan, I. Supplier evaluation and management system for strategic sourcing based on a new multicriteria sorting procedure. Int. J. Prod. Econ. 2007, 106, 585-606. [CrossRef]

66. Figueira, J.J.R.; De Smet, Y.; Brans, J.P. MCDA Methods for Sorting and Clustering Problems: Promethee TRI and Promethee CLUSTER; Universite Libre de Bruxelles: Bruxelles, Belgium, 2005.

67. de Oliveira Silva, L.G.; de Almeida-Filho, A.T. A new PROMETHEE-based approach applied within a framework for conflict analysis in Evidence Theory integrating three conflict measures. Expert Syst. Appl. 2018, 113, 223-232. [CrossRef]

68. Gomes, C.F.S.; dos Santos, M.; Teixeira, L.F.H.D.S.D.B.; Sanseverino, A.M.; Barcelos, M.R.D.S. SAPEVO-M: A GROUP MULTICRITERIA ORDINAL RANKING METHOD. Pesqui. Oper. 2020, 40, 1-20. [CrossRef]

69. Gomes, L.F.A.M.; Mury, A.R.; Gomes, C.F.S. Multicriteria ranking with ordinal data. Syst. Anal. Model. Simul. 1997, 27, 139-145.

70. Liao, H.; Wu, X. DNMA: A double normalization-based multiple aggregation method for multi-expert multi-criteria decision making. Omega 2020, 94, 102058. [CrossRef]

71. Gawlik, R. Methodological Aspects of Qualitative-Quantitative Analysis of Decision-Making Processes. Manag. Prod. Eng. Rev. 2016, 7, 3-11. [CrossRef]

72. Koornneef, H.; Verhagen, W.J.C.; Curran, R. A decision support framework and prototype for aircraft dispatch assessment. Decis. Support Syst. 2020, 135, 113338. [CrossRef]

73. Moreira, M.Â.L.; dos Santos, M.; Gomes, C.F.S. PROMETHEE-SAPEVO-M1 Software Web (v.1). 2020. Available online: www.promethee-sapevo.com (accessed on 27 January 2021).

74. Wu, Y.; Xu, C.; Ke, Y.; Chen, K.; Sun, X. An intuitionistic fuzzy multi-criteria framework for large-scale rooftop PV project portfolio selection: Case study in Zhejiang, China. Energy 2018, 143, 295-309. [CrossRef]

75. Roy, B.; Figueira, J.R.; Almeida-Dias, J. Discriminating thresholds as a tool to cope with imperfect knowledge in multiple criteria decision aiding: Theoretical results and practical issues. Omega 2014, 43, 9-20. [CrossRef]

76. Podvezko, V.; Podviezko, A. Dependence of multi-criteria evaluation result on choice of preference functions and their parameters. Technol. Econ. Dev. Econ. 2010, 16, 143-158. [CrossRef]

77. Bouyssou, D. Building Criteria: A Prerequisite for MCDA. In Readings in Multiple Criteria Decision Aid; Springer: Berlin/Heidelberg, Germany, 1990; pp. 58-80.

78. Almeida, A.T.; Cavalcante, C.A.V.; Alencar, M.H.; Ferreira, R.J.P.; de Almeida-Filho, A.T.; Garcez, T.V. Multicriteria and Multiobjective Models for Risk, Reliability and Maintenance Decision Analysis, 1st ed.; Springer: New York, NY, USA, 2015; ISBN 978-3-319-17968-1.

79. BELL BELL AH-1Z. Available online: https:/ / www.bellflight.com/military/bell-ah-1z (accessed on 27 January 2021).

80. TURKISH AEROSPACE T129 ATAK. Available online: https://www.tai.com.tr/en/product/t129-atak (accessed on 27 January 2021).

81. RUSSIAN HELICOPTERS Mi-35M. Available online: http:/ / www.russianhelicopters.aero/en/helicopters/military/mi-35m. html (accessed on 27 January 2021).

82. HELIBRAS Tiger HAD. Available online: https:/ / www.helibras.com.br/website/po/ref/Tiger_39.html (accessed on 27 January 2021).

83. BOEING AH-64 Apache. Available online: https:/ / www.boeing.com/defense/ah-64-apache/ (accessed on 27 January 2021).

84. Airbus The H160M for the French Armed Forces. Available online: https:/ / www.airbus.com/helicopters/military-helicopters/ medium/h160M.html (accessed on 27 January 2021).

85. Aires, R.F.D.F.; Ferreira, L. The rank reversal problem in multi-criteria decision making: A literature review. Pesqui. Oper. 2018, 38, 331-362. [CrossRef]

86. Mareschal, B. Visual PROMETHEE; Universite Libre de Bruxelles: Bruxelles, Belgium, 2011.

87. Cinelli, M.; Kadziński, M.; Gonzalez, M.; Słowiński, R. How to support the application of multiple criteria decision analysis? Let us start with a comprehensive taxonomy. Omega 2020, 102261. [CrossRef] [PubMed]

88. Parreiras, R.O.; Ekel, P.Y.; Martini, J.S.C.; Palhares, R.M. A flexible consensus scheme for multicriteria group decision making under linguistic assessments. Inf. Sci. 2010, 180, 1075-1089. [CrossRef]

89. Costa, A.S.; Rodrigues, R.; Xiang, A.; Figueira, J.R.; Borbinha, J. Supporting the Use of Decision Aiding Methods by Nonspecialists. In Proceedings of the International Symposium on Business Modeling and Software Design, Lisbon, Portugal, 1-3 July 2019; pp. 81-94. 